\title{
Observation of the process of snow accumulation on the Antarctic Plateau by time lapse laser scanning
}

\author{
Ghislain Picard $^{1}$, Laurent Arnaud ${ }^{1}$, Romain Caneill ${ }^{1, a}$, Eric Lefebvre ${ }^{1}$, and Maxim Lamare ${ }^{1}$ \\ ${ }^{1}$ UGA, CNRS, Institut des Géosciences de l'Environnement (IGE), UMR 5001, Grenoble, 38041, France \\ a now at: Department of Marine Sciences, University of Gothenburg, Gothenburg, Sweden \\ Correspondence: Ghislain Picard (ghislain.picard@univ-grenoble-alpes.fr)
}

Received: 7 January 2019 - Discussion started: 14 January 2019

Revised: 14 May 2019 - Accepted: 28 June 2019 - Published: 17 July 2019

\begin{abstract}
Snow accumulation is the main positive component of the mass balance in Antarctica. In contrast to the major efforts deployed to estimate its overall value on a continental scale - to assess the contribution of the ice sheet to sea level rise - knowledge about the accumulation process itself is relatively poor, although many complex phenomena occur between snowfall and the definitive settling of the snow particles on the snowpack. Here we exploit a dataset of near-daily surface elevation maps recorded over 3 years at Dome $\mathrm{C}$ using an automatic laser scanner sampling $40-100 \mathrm{~m}^{2}$ in area. We find that the averaged accumulation is relatively regular over the 3 years at a rate of $+8.7 \mathrm{~cm} \mathrm{yr}^{-1}$. Despite this overall regularity, the surface changes very frequently (every $3 \mathrm{~d}$ on average) due to snow erosion and heterogeneous snow deposition that we call accumulation by "patches". Most of these patches (60\%-85\%) are ephemeral but can survive a few weeks before being eroded. As a result, the surface is continuously rough $(6-8 \mathrm{~cm}$ root-meansquare height) featuring meter-scale dunes aligned along the wind and larger, decameter-scale undulations. Additionally, we deduce the age of the snow present at a given time on the surface from elevation time series and find that snow age spans over more than a year. Some of the patches ultimately settle, leading to a heterogeneous internal structure which reflects the surface heterogeneity, with many snowfall events missing at a given point, whilst many others are overrepresented. These findings have important consequences for several research topics including surface mass balance, surface energy budget, photochemistry, snowpack evolution, and the interpretation of the signals archived in ice cores.
\end{abstract}

\section{Introduction}

The accumulation of snow and ice on the Antarctic ice sheet is a major component of its mass balance. Many studies aim to estimate the accumulation rate at regional or continental scales. They use in situ observations and interpolation (Favier et al., 2013), various satellite observations (Vaughan et al., 1999; Arthern et al., 2006), regional and global climate models (Krinner et al., 2006; Lenaerts et al., 2012; Agosta et al., 2019), and ever more a combination of these. A relative consensus on the present annual accumulation has been reached (The IMBIE team, 2018). However, this is not the case for future projections, which can only rely on climate modeling. Even though the models are extensively evaluated against current observations, they are biased and some processes may have a different influence in the future, potentially reducing the models' skills.

This important attention paid to the accumulation quantification contrasts with the limited number of investigations on the process of accumulation itself. This process appears to be more complex in Antarctica compared to other regions (mountains, sea ice, etc.). Snowfall is the main process of mass gain for the surface, but the direct deposition of water vapor on and in the snowpack can be significant as well (Krinner et al., 2006), although this is debated (Agosta et al., 2019). Sublimation is the main process of mass loss, but it is associated with large uncertainties highlighted by the very wide range of estimates in the literature obtained by modeling, from a few percent to half of the precipitation amount (Déry and Yau, 2002; Lenaerts et al., 2010, 2012). Moreover, some recent in situ and remote-sensing observations (Gallet et al., 2014; Grazioli et al., 2017) have revealed underappreciated sublimation components (at the surface or in the atmo- 
sphere) that are not yet present in models. Transport of snow by wind has an uncertain contribution on the overall surface mass balance (SMB) of the ice sheet with two effects: (1) the advection of snow out of the ice sheet to the ocean and (2) enhancement of airborne snow sublimation, which is thought to be very significant (Gallée et al., 2001) but still uncertain (Sharma et al., 2018). Transport also has an important role on snow distribution at small scales, though this does not affect the overall SMB of the ice sheet.

At the meter scale, the Antarctic surface is generally shaped by the wind (Furukawa et al., 1996). Erosion plays a prominent role by scouring deposited snow and forming sastrugi. The deposition is also highly heterogeneous, leading to the formation of semiorganized wavelike features on the surface. Namely these are often classified as longitudinal dunes, barchan dunes, whalebacks, ripples, etc (Filhol and Sturm, 2015). The horizontal length scale of these features ranges from a few centimeters up to hundreds of meters (Frezzotti et al., 2002; Picard et al., 2014; Kochanski et al., 2018), and their height is typically $10-100 \mathrm{~cm}$. Interestingly, on the Antarctic Plateau this height is generally orders of magnitude larger than the averaged amount of snow accumulated during a single snowfall event, and can even be larger than the mean annual accumulation. It results that erosion can exceed accumulation in some points for some years, a situation referred to as "accumulation hiatus" (Petit et al., 1982). Annual net accumulation data obtained from stake networks at Dome $\mathrm{C}\left(75^{\circ} \mathrm{S}, 123^{\circ} \mathrm{E}\right)$ indeed show a wide distribution of values, including some negative ones (Picard et al., 2016). These traits are specific to the dry and windy Antarctic.

The representation of the accumulation process is usually done in a simplified way in large-scale climate models (e.g., LMDz global circulation model; Krinner et al., 2006) and in small-scale snow evolution models (e.g., Crocus, Vionnet et al., 2012 and SNOWPACK Lehning et al., 1999): snow is accumulated on the surface in successive layers (1-D model) added at the time of the snowfall. This reflects the accumulation process as commonly observed in alpine regions. However, this representation is inadequate to account for the aforementioned Antarctic traits. Recent works tried to improve modeling with more complex deposition schemes. Based on snowfalls recorded at Dome C, Groot Zwaaftink et al. (2013) noticed that nearly half of the snowfall events did not result in visible accumulation on the ground. This was explained by the fact that fresh snow is easily remobilized. They accordingly modified the SNOWPACK model, by storing snowfall in a virtual reservoir until a strong wind event triggered its release. The time elapsed in this virtual reservoir could be as long as several days. The snow was then accumulated in layers on the surface where it remained permanently as in any 1-D model, neglecting erosion. Libois et al. (2014) took a different approach with an intent to simulate the spatial variability of snow properties observed in snow pits. They ran 50 simulations of the 1-D Crocus model in parallel. Each simulation represented a decameter-scale cell but there was neither spatial organization nor notion of neighborhood between the cells. The simulations were mostly independent except that they received a different amount of snow during each snowfall and they exchanged snow during strong wind events (local erosion and redeposition). These two processes were implemented using stochastic rules, adjusted to mimic some in situ observations collected at Dome C. The approach was quite successful in reproducing the variability observed in 100 profiles of snow density and specific surface area collected during a summer campaign. However, their rules lack a physical basis and were empirically parameterized with a limited set of observations.

The aforementioned pioneering modeling studies are limited by the scarcity of observations providing detailed information on the accumulation process. Here, we exploit a new dataset of daily surface elevation maps obtained with an automatic ground-based laser scanner at Dome C (Picard et al., 2016) scanning a surface area of $40-100 \mathrm{~m}^{2}$ and which operated during 3 years. The aim is to answer three main questions. (1) What are the spatial and temporal characteristics of the accumulation patterns? (2) How long does snow remain on the surface before being eroded or definitely incorporated in the snowpack? (3) What is the impact of the accumulation process on the snowpack's upper internal structure? The study focuses on the meter scale and daily to annual timescale and follows a statistical approach to describe the accumulation and erosion patterns and their dynamics. The paper is organized as follows: Sect. 2 presents the data and the algorithms developed to extract information (accumulation, age of the snow on the surface, etc.) from the series of elevation maps, Sect. 3 presents the results, and Sect. 4 provides a discussion.

\section{Materials and method}

\subsection{Rugged LaserScan (RLS)}

The Rugged LaserScan (RLS) is composed of a lasermeter mounted on a two-axis rotation stage to perform the elevation and azimuthal rotations, enabling 2-D scanning of the surface. It is described in detail in Picard et al. (2016) and only limited information is recalled here. The lasermeter (Dimetix FLS-CH 10) measures the radial distance to the snow surface with an intrinsic accuracy of $\pm 2 \mathrm{~mm}$ (statistical confidence level of $95.4 \%$ ), which proved to be effective for a wide range of illumination and temperature conditions (Picard et al., 2016). To achieve this constant accuracy however, the rate of measurements, of $20 \mathrm{~Hz}$ in optimal conditions, is automatically reduced when the conditions are unfavorable (high luminosity, blowing snow, rapidly changing surface). The consequence for our particular setup where the lasermeter is rotated at a constant speed is a reduced spatial resolution. We also found that despite a design for outdoor operations, the lasermeter performance during the daytime 
was greatly improved by adding a band-pass optical filter at the laser operating wavelength $(650 \mathrm{~nm})$ on the optical window. The lasermeter is heated with internal components and regulated at $0{ }^{\circ} \mathrm{C}$ for maximal stability of the internal time reference. We fitted an additional heating patch $(20 \mathrm{~W})$ on the external box, enabling operations at temperatures as low as $-80{ }^{\circ} \mathrm{C}$, which also contributes to the removal of the frost and snow (by sublimation) that occasionally builds up on the device.

The two-axis stage is composed of two identical motors controlled by a feedback loop on the position (servomotor). The precision and accuracy are of the order of 0.03 and $0.1^{\circ}$, respectively, which is small but nonetheless is the main limiting factor in terms of accuracy. The scan is performed by moving the azimuth (horizontal) stage at constant speed from nearly -90 to $+90^{\circ}$, then by increasing the zenith angle (angle from the vertical axis) by a small increment, and finally by moving the stage back from +90 to $-90^{\circ}$. The process is repeated many times for zenith angles from 17 up to $62^{\circ}$. The increment in zenith angle and the speed in azimuth are not constant as they are calculated to obtain a uniform measurement sampling over the whole area. Nevertheless the resolution effectively obtained also depends on the actual lasermeter rate, which can vary a lot. A normal scan contains about 200000 points and takes a total of $4 \mathrm{~h}$ to complete.

Scanning is scheduled at 21:00 local time $(\mathrm{GMT}+8)$ every day to avoid high-illumination conditions. However, not all the scans are completed with sufficient points to produce a useful map. The main reasons include (1) downtime due to major failures of the RLS or for maintenance, (2) snow or frost deposition on the laser window, and (3) blowing snow crystals intercepting the laser beam, which greatly reduces the acquisition rate. The two latter causes of failure obviously occur during or after snowfalls and blowing snow events. This results in fewer valid scans in the periods of greater surface change. This correlation between the observation quality and the observed phenomenon represents a potential source of bias which must be kept in mind for the analysis. Other, more occasional, reasons of scan failure include power supply shutdowns and interruptions of the scanning process due to undocumented errors raised by the lasermeter.

The RLS was operating at Dome C (Fig. 1; see also Picard et al., 2016) over two periods with different configurations (Table 1). From 1 January 2015 to 17 January 2016, it was set up at a height of $2.8 \mathrm{~m}$ (period 1). A major failure occurred during this period between 17 October and 5 December 2015 (49d). After the maintenance during the summer campaign, it was reinstalled at a height of $4.5 \mathrm{~m}$ (period 2) on 1 February 2016. Because of the difference in height during periods 1 and 2, the scanned area is different: $40 \mathrm{~m}^{2}$ and $110 \mathrm{~m}^{2}$, respectively, and the effective spatial resolution was accordingly adjusted to 2 and $3 \mathrm{~cm}$, respectively. Although the area scanned during period 1 was located inside the area scanned during period 2 , no attempt to co-register the two was made. The two time series are interpreted as indepen-

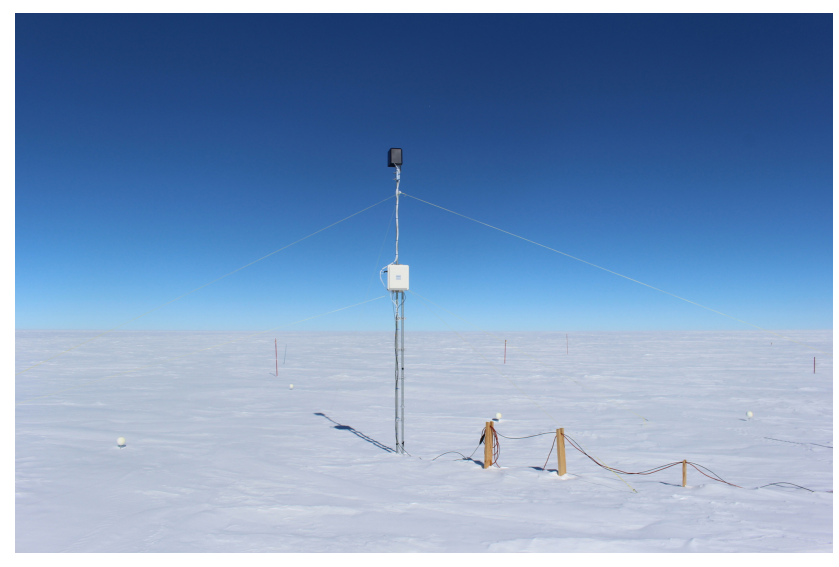

Figure 1. The RLS setup at Dome C (January 2017). The lasermeter and rotation mount are located under the black cap. The control is in the white box. The photograph looks southward, facing prevailing winds, and the scanned area is behind the RLS mast.

dent datasets. Only the mean surface elevation at the end of period 1 is taken as reference for shifting the starting elevation of period 2 in order to get a continuous mean elevation time series. Furthermore, after a year of operation in period 2, the outer sheath of the lasermeter cable was damaged by the recurring friction during the azimuthal rotations. The electric contacts became less and less reliable. Nonetheless, the lasermeter continued to operate but returned a decreasing number of valid data until the dismounting on 28 January 2018. Because of the random nature of the problem, a few scans are useful, at least to estimate the mean elevation of the surface. Hence, we split period 2 into a first high-quality part, named $2 \mathrm{a}$, and a second part named $2 \mathrm{~b}$ where only the few best scans are selected (Table 1). Despite a much lower temporal resolution, the period $2 \mathrm{~b}$ time series still provides a useful extension of nearly a year. In the following, we mainly use period 2a for its finer temporal resolution and wider scanned area, while periods 1 and $2 b$ are only exploited to investigate the general trends over the 3 years.

\subsection{RLS precision and stability}

To capture the small accumulation that occurs at Dome C, the accuracy and precision of the instrument are critical. In Picard et al. (2016) we estimated the vertical long-term absolute accuracy to be better than $1 \mathrm{~cm}$ over period 1 . This is reasonably low compared to the annual accumulation (approximately $8 \mathrm{~cm}$ ). To achieve such long-term stability, the mast was anchored to a wooden board $(50 \mathrm{~cm} \times 50 \mathrm{~cm})$ buried at a depth of $1 \mathrm{~m}$. The mast was secured with three Dyneema SK78 ropes ( $3 \mathrm{~mm}$ in diameter) during period 1 and with six ropes on two levels during period 2 (as shown in Fig. 1). These ropes have a small wind surface area, low stretchability due to creep and weak thermal dilatation. We also es- 
Table 1. RLS configuration and performance for different periods.

\begin{tabular}{llll}
\hline Period name & Dates & Height (scanned area) & $\%$ success \\
\hline 1 & 1 Jan 2015 to 17 Jan 2016 & $2.8 \mathrm{~m}\left(40 \mathrm{~m}^{2}\right)$ & $65 \%$ \\
2a & 1 Feb 2016 to 11 Feb 2017 & $4.5 \mathrm{~m}\left(110 \mathrm{~m}^{2}\right)$ & $79 \%$ \\
$2 \mathrm{~b}$ & 12 Feb 2017 to 25 Dec 2017 & $4.5 \mathrm{~m}\left(110 \mathrm{~m}^{2}\right)$ & $16 \%$ \\
\hline
\end{tabular}

timated over period 1 that the precision (or reproducibility) between successive measurements was better than $0.5 \mathrm{~cm}$.

Since the RLS was set up higher during period 2, we briefly reevaluate the accuracy here. Figure 2 shows the vertical movements of the calibration spheres (visible in the photograph in Fig. 1; see details in Picard et al., 2016). Four spheres were installed at the beginning of period 1 in the scanned area, and during period 2 only two of them remained in the scanned area, high enough above the surface to be detected, and one was added. The results show apparent movements of up to $2-4 \mathrm{~cm}$ in maximum amplitude over the 2 years and $0.28-0.68 \mathrm{~cm}$ rms over period $1-$ depending on the sphere, so $0.5 \mathrm{~cm}$ on average for the available spheres and $0.49-0.81 \mathrm{~cm} \mathrm{rms} \mathrm{over} \mathrm{period} 2$. We can estimate that the slow variations and some of the sharp variations are caused by the imperfect stability of the mast and, as noticed by the winter-over staff, by the formation and removal of hoar on the spheres (about $1 \mathrm{~cm}$ thick) (Champollion et al., 2013). Conversely, most of the rapid variations are likely caused by instrumental errors and the uncertainty in the detection of the spheres. The rapid variations can be quantified by computing the standard deviation of the sphere elevation changes between every successive scan. We find variations of $0.16-$ $0.24 \mathrm{~cm} \mathrm{rms}$ and $0.38-0.62 \mathrm{~cm} \mathrm{rms}$ for the two periods. The largest value is obtained for sphere 5 , which is at the furthest edge of the scanned area, and thus represents the most challenging conditions to retrieve the elevation. These values provide the upper limits of the instrument error.

Another approach to estimate the non-systematic instrument error can be based on the measured rms change between successive acquisitions, which is the sum of the real rms changes and the rms variations due to the instrument error. We can thus estimate the latter when the surface has been subject to no real change, i.e., when the first term is null. Because both terms are strictly positive, we can estimate the rms variations caused by instrumental errors by searching for the minimum rms changes over the time series (i.e., standard deviation of daily accumulation) and assume that for that day, the surface did not change. For periods 1 and 2, respectively, we find minimum rms variations of 0.03 and $0.13 \mathrm{~cm}$, which are very low values. These estimates are representative of the most favorable conditions (calm air), as it is likely that windy conditions always provoke real changes, and thus cannot lead to a minimum rms. We therefore conclude that the actual instrument error that most affects our daily accumulation is between the estimate derived from the spheres and the estimate derived using the minimum variations in rms, say around 0.2 and $0.4 \mathrm{~cm}$ for periods 1 and 2 , respectively.

\subsection{RLS data processing}

Processing the raw data to produce elevation maps on a common and regular grid is performed in several steps. For each single acquisition, raw data comprise the radial distance and two angles (azimuth and zenith). After filtering the obviously erroneous distances (less than $3 \mathrm{~m}$ or more than $17 \mathrm{~m}$ ), the data are projected into Cartesian coordinates $(x, y)$ with $z$ the vertical axis. $z(x, y)$ is the surface elevation. A second filter is applied to remove the points $(x, y)$ with fewer than two neighbors in a $5 \mathrm{~cm}$ radius circle centered at $(x, y)$ and with $|z(x, y)-\bar{z}|>5 \mathrm{~cm}$, where $\bar{z}$ is the averaged elevation of the neighbors. This operation removes outliers and small objects like blowing crystals or the RLS mast guylines. This set of curated but irregularly spaced points is then interpolated onto a regular grid using the bilinear method interpolation provided by the matplotlib.mlab.griddata Python function (version 2.2). The grid spacing is set to 2 and $3 \mathrm{~cm}$, respectively, for periods 1 and 2, in relationship with the different setup heights. To avoid filling large gaps with the bilinear interpolation, a grid point was attributed a valid $z$ value only if at least one measurement was taken within twice the grid spacing (i.e., 4 and $6 \mathrm{~cm}$ for periods 1 and 2 respectively) around it. In practice, we found that $93 \%(62 \%)$ of the grid points have at least one measurement within one (half) grid spacing. If the final map contained fewer than 100000 valid grid points, it was completely discarded. All these operations yield a time series of elevation maps on a common grid. The grid orientation was determined by observing the shadow of the RLS mast in the scanned area. We found that the $x$ axis lies towards $116^{\circ}$ (east-southeast), which allowed us to draw the southern direction on the maps. Note that this orientation was chosen to minimize the perturbation of the mast on the surface, the prevailing winds being from the southeastsouthwest sector.

Various additional datasets are then derived from the generated maps. The accumulation between every successive scan is calculated as the difference between the elevation for each point of the grid. In most cases, both scans are acquired $1 \mathrm{~d}$ apart (90\% over period $2 \mathrm{a}$ ) so the computed accumulation is representative of the daily variation. However, due to scan failure or rejection during the processing, longer time intervals are present in the time series $(2 \mathrm{~d}$ in $7 \%$ of the cases, 


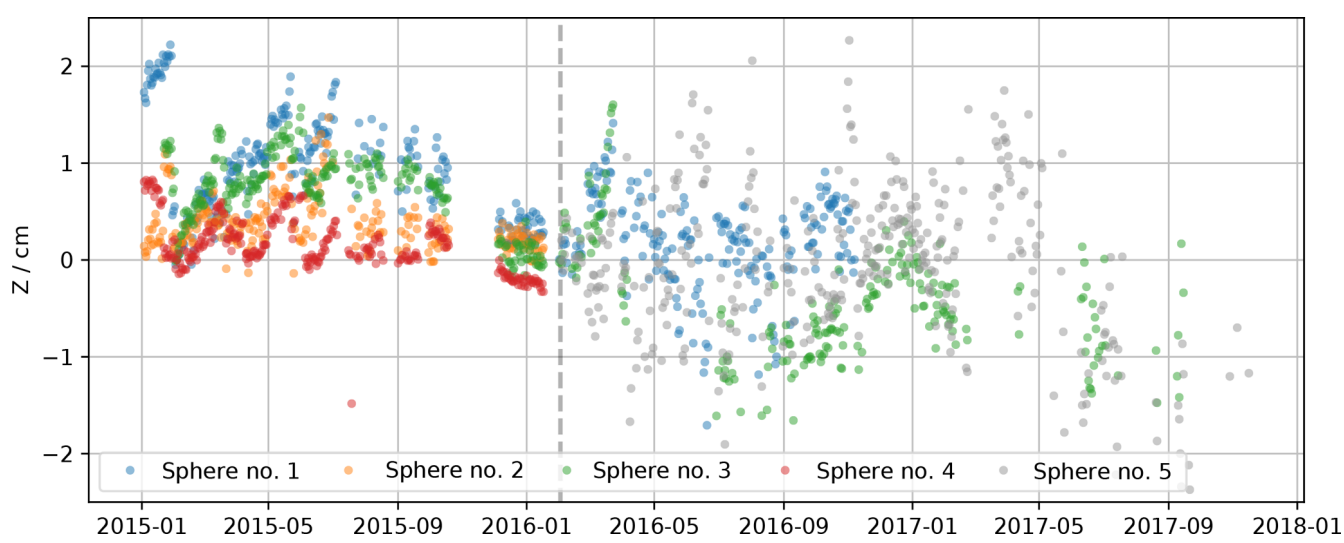

Figure 2. Evolution of the elevation of five calibration spheres set up in the scanned area at the beginning of period 1 . The gray dashed line shows the beginning of period 2 .

and 3-9d in the remaining $3 \%$ ). We nevertheless interpret the accumulation time series as if it were daily accumulation only.

The age of the snow on the surface is another dataset derived from the elevation maps. The algorithm is applied independently for each point as follows. For each point, the age is initialized to 0 . For each date $i$ the accumulation $a_{i}$ since the last detected deposition or erosion event (or the beginning of the time series) is calculated. If $a_{i}$ is larger than a given positive threshold $\delta_{\mathrm{a}},\left(a_{i} \geq \delta_{\mathrm{a}}\right)$, there was deposition of new snow, and the age is reset to 0 . If this value is lower than a negative threshold $\delta_{\mathrm{e}}\left(a_{i}<\delta_{\mathrm{e}}\right)$, snow was removed by erosion, and for values between both thresholds $\left(\delta_{\mathrm{e}} \leq a_{i}<\delta_{\mathrm{a}}\right)$, the variation is considered insignificant and the age is incremented by the time elapsed since the previous available date. In the case of erosion, the algorithm then searches back in time for the first date $j$ for which the elevation was equal (or closest below) to the present elevation at the point. The snow present at the surface at date $j$ now emerges again. The age of this snow is calculated as its age at date $j$ plus the time elapsed since $j$, that is $i-j$. We choose a threshold value $\delta_{\mathrm{a}}=1 \mathrm{~cm}$ which tends to avoid sporadic age change for small variations (possibly due to residual noise) and $\delta_{\mathrm{e}}=0$. This algorithm is robust because even if $\delta_{\mathrm{a}}$ is chosen too close to the noise level, age errors are not accumulated over time, and only the statistics of the age at a given date may be affected. A low threshold tends to bias the age distribution towards younger snow due to the overestimation of new snow accumulation. To illustrate the sensitivity we also present results for $\delta_{\mathrm{a}}=0.5 \mathrm{~cm}$ and $\delta_{\mathrm{e}}=-0.5 \mathrm{~cm}$.

In addition to the age, we derive the time of residence on the surface, which is the same as the age except that when erosion is detected, the time on the surface at time $i$ is taken as equal to the time on the surface at time $j$, not counting the time spent while buried $(i-j)$. We also derive the time of residence before erosion, which is equal to the time spent on the surface just before erosion is detected.

\subsection{Meteorological data}

Meteorological data are used to relate surface changes and weather. We use precipitation forecast provided by the ERAInterim reanalysis (ERA-I) (Dee et al., 2011) near Dome C. Due to the absence of reliable methods to record in situ precipitation in Antarctic conditions, ERA-I is one of the most reliable sources of information to date (Bromwich et al., 2011), though it is known to underestimate accumulation near Dome C (Genthon et al., 2015; Wang et al., 2016). For wind speed and direction, we use data from the weather station at Concordia station $\left(75.1^{\circ} \mathrm{S}, 123.3^{\circ} \mathrm{E}, 3230 \mathrm{~m}\right.$ a.s.l., http://www.climantartide.it/, last access: 15 July 2019). Over the 3 years, the mean wind speed at $3 \mathrm{~m}$ is $7 \mathrm{~m} \mathrm{~s}^{-1}$, which is higher than the ERA-I prediction of $5.2 \mathrm{~m} \mathrm{~s}^{-1}$ at $10 \mathrm{~m}$. Nevertheless, both sources agree on the temporal variations, with a correlation of 0.8 , which is the most important point for our comparison. The wind regime at Dome $\mathrm{C}$ is characterized by a prevailing direction from the south $(74 \%$ of the time), the most likely direction being $190^{\circ}$. The distribution and maximum remain identical when selecting only strong winds (e.g., over the mean, $7 \mathrm{~m} \mathrm{~s}^{-1}$ ), which are relevant for this study.

\section{Results}

The RLS dataset is studied first by addressing the general characteristics of the elevation changes (Sect. 3.1) and annual accumulation over the whole area (Sect. 3.2), and then focusing on the smaller temporal and spatial scales (Sect. 3.3, 3.4 and 3.5). Lastly, we investigate the internal structure of the snowpack deduced from the elevation changes (Sect. 3.6). 


\subsection{Surface elevation changes}

The elevation of the surface averaged over the scanned area generally increases with time at a mean rate of $8.7 \mathrm{cmyr}^{-1}$ (Fig. 3). However, different dynamics are observed for the different years. As noted by Picard et al. (2016) for the first year, a unique and marked accumulation event occurred in the period 4-16 July 2015, which accounted for most of the annual accumulation during that year. In contrast, the second and third years of the dataset feature a fairly regular increase in the surface elevation, suggesting the absence of dramatic accumulation events. Interestingly, this regularity in the cumulative precipitation is also found in the ERA-I forecast (Fig. 3, green curve) with a remarkable absence of seasonal signal despite the huge variations in temperature between summer (typ. $-25^{\circ} \mathrm{C}$ ) and winter (typ. $-70^{\circ} \mathrm{C}$ ). However, the precipitation in ERA-I is overall too weak with only $16 \mathrm{~kg} \mathrm{~m}^{-2} \mathrm{yr}^{-1}$ over the 3 years. This mass is equivalent to only $5 \mathrm{~cm} \mathrm{yr}^{-1}$ of snow taking a typical surface density value of $320 \mathrm{~kg} \mathrm{~m}^{-3}$ for the conversion (Genthon et al., 2015; Picard et al., 2014; Leduc-Leballeur et al., 2017). The missing mass in ERA-I could be due to underestimation of the synoptic precipitation or of the deposition that seems indeed very low (Genthon et al., 2015) compared to that reported by other sources (Krinner et al., 2006; Agosta et al., 2019).

The root-mean-square height of the surface (rms height, calculated as the standard deviation of the surface elevation) is shown in Fig. 3 as a blue shaded area. Physically, this metric measures the amplitude of the elevation variations over the scanned area including all the spatial scales of variations, that is, those due to the meter-scale roughnesses, the local slope, and potential instrumental artifacts (such as the repeatability error of the RLS). Overall, the rms height has a large magnitude compared to the annual accumulation. Over the 3 years, it was smaller $(4 \mathrm{~cm})$ at the beginning of the first season, before the event in July 2015, where it nearly doubled and remained fairly constant after that, with $7-8 \mathrm{~cm}$. In particular it remained constant during the shift periods 1 and 2a, despite a 3 -fold increase in the scanned area. These numbers are significant compared to the instrumental error (Sect. 2.2), except during the last period ( $2 b$ ), where we believe the standard deviation is unreliable, and probably affected by the failures of the RLS.

To estimate the respective role of the meter-scale roughness and the local slope over the scanned area, we fitted a plane on each scan using the least-square method. The local slope is fairly constant, of the order of $1-1.5^{\circ}$ over the time series, indicating that a large-scale terrain undulation was present. In comparison, the Dome $\mathrm{C}$ area has a very small overall slope, less than $1 \mathrm{~m}$ per kilometer $\left(0.06^{\circ}\right)$. Once the plane is subtracted from the elevation map, the rms height is reduced by about half, implying that half of the elevation variations are attributed to meter-scale roughness (typically sastrugi and small dunes) whilst the other half are caused by terrain undulation (e.g., decameter-scale dunes;
Picard et al., 2014). It is finally worth noting the absence of seasonal signals in the roughness evolution, which differs from reports for other locations on the ice sheet (Gow, 1969; Adodo et al., 2018).

\subsection{Spatial characteristics of the annual accumulation}

Figure 4 shows the statistical distribution of annual accumulation over the scanned area. The three periods, corresponding roughly to the years 2015,2016 , and 2017, present different patterns. In 2015, the mean accumulation is $7.7 \mathrm{~cm}$ and the highest accumulation is nearly $30 \mathrm{~cm}$. Negative accumulation concerns $12 \%$ of the surface. The second year highlights a significantly higher mean accumulation with $10.0 \mathrm{~cm}$ ( $+31 \%$ compared to 2015), which is also present in ERA-I $(+50 \%$ precipitation). It results that almost no negative accumulation is observed, but more surprisingly the maximum accumulation is reduced compared to 2015, from 30 to about $22 \mathrm{~cm}$. The accumulation distribution in 2016 looks Gaussian and narrow in contrast to the two other years showing a wider and more asymmetrical distribution. The last year has the same mean accumulation as the first one, but fewer negative accumulation values and a lower maximum accumulation, of the order of $22 \mathrm{~cm}$.

In Picard et al. (2016), the distribution of annual accumulation estimated over the RLS area of $40 \mathrm{~m}^{2}$ in 2015 was noticed to be surprisingly similar to the distribution obtained from the GLACIOCLIM stake network, which is composed of 50 measurement points about $10 \mathrm{~m}$ apart, thus covering a much more extensive area. Figure 4 further confirms this finding for the two last years (2016 and 2017). This remarkable result indicates that despite the small extent of the RLS scanned area, the distribution of net annual accumulation may be representative of a wider area.

\subsection{Spatial and temporal characteristics of the daily accumulation}

The mean and standard deviation of accumulation (noted $\bar{A}$ and $\sigma_{A}$, respectively) between every two consecutive dates (called daily accumulation here despite the irregular sampling in time) were calculated and compared to precipitation (from ERA-I), wind speed, and direction (from the Concordia Automatic Weather Station). Figure 5 shows scatter plots between these variables (except wind direction as no interesting signal was found). Overall, there is little correlation, if any, between the variables, which is unexpected because in many regions of the world the daily accumulation is strongly related to precipitation (e.g., Alpine regions), and in Antarctica the role of the wind has been emphasized (Groot Zwaaftink et al., 2013). This role may be the reason why in the bottom left plot in Fig. 5, points are scarce above the orange line delineating a domain with low-wind and high surface change. This indicates that some wind is necessary to induce surface change, which is obvious, though the statisti- 


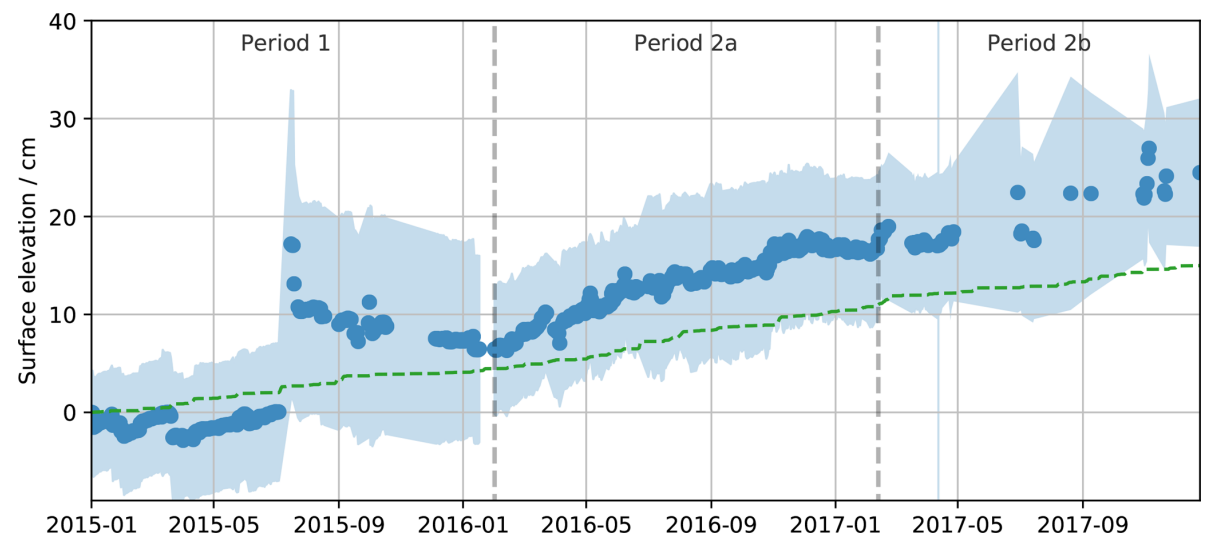

Figure 3. Evolution of the mean surface elevation and rms height in the scanned area observed by RLS (blue) and of the cumulative precipitation forecast from ERA-Interim at Dome C (green) converted in snow depth assuming a surface density of $320 \mathrm{~kg} \mathrm{~m}^{-3}$. The blue shade shows $\pm 1 \mathrm{rms}$ height around the mean.
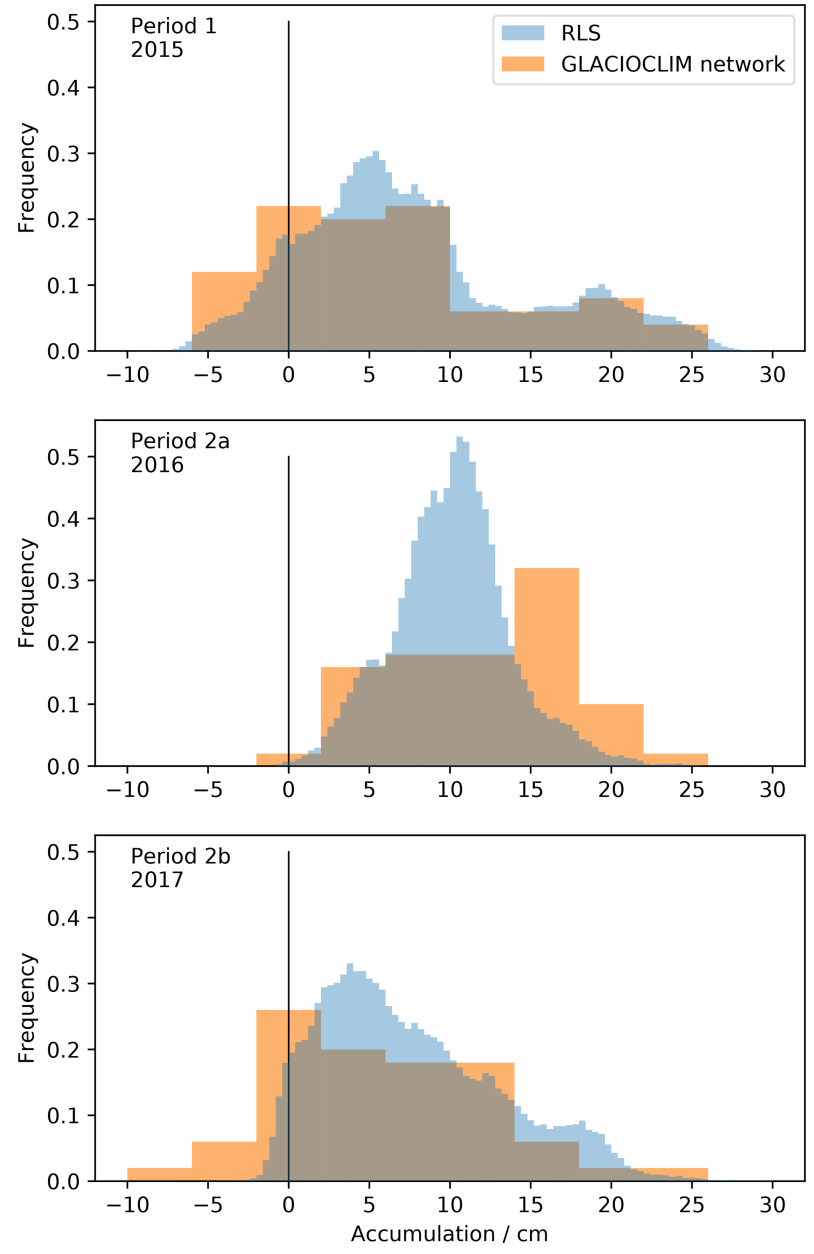

Figure 4. Distribution of the annual accumulation in the scanned area (blue bars) and from the 50 stakes of the GLACIOCLIM network near Dome C (orange bars). cal relationship is probably not robust. Another interesting and more robust pattern is visible in the bottom right plot showing the mean and standard deviation of the accumulation. This pattern indicates that significant (positive or negative) mean accumulations are always associated with high standard deviations over the area, which can be expressed mathematically by $\sigma_{A}>|\bar{A}|$. We interpret this relationship by the fact that (1) many events change the surface but do not affect the overall mass in the area $\left(\sigma_{A} \gg|\bar{A}| \approx 0 \mathrm{~cm}\right)$ and (2) that the events leading to significant accumulation or erosion cause highly heterogeneous changes over the area (with both negative and positive changes). Conversely, the process of accumulation or erosion by "layer" (which would correspond to $\sigma_{A} \ll|\bar{A}|$ ) does not exist at Dome C. However this relationship does not link accumulation to meteorological conditions.

This result suggests that further investigation concerning the positive and negative changes in surface elevation at every point is necessary. Figure 6 shows the cumulated sum (average over the scanned area) of daily accumulation considering either only the increments (deposition above 0, 0.5, or $2 \mathrm{~cm}$ ) or the decrements (erosion higher than $0,0.5$, and $2 \mathrm{~cm}$ ). To account for the instrumental error in the data, we have estimated for each increment $a$ (or decrement) the probability of the presence of an error by assuming that the error follows a normal distribution with a standard deviation of $0.4 \mathrm{~cm}$ (Sect. 2.2), and with the probability set to 1 for $0 \mathrm{~cm}$ increments, that is $p(a)=\exp \left(\frac{-a^{2}}{2 \sigma_{\mathrm{a}}^{2}}\right)$. We then randomly removed every increment $a$ in the proportion of the probability $p(a)$, that is, given $x \sim \mathcal{U}(0,1)$, the increment $a$ is rejected if $x<p(a)$. The figure also shows the net cumulative accumulation for comparison, which is exactly the same as the mean surface elevation changes in Fig. 3. Over the 1-year period, each pixel has received a total of $55 \mathrm{~cm}$ of snow on average. Most of it has been removed $(47 \mathrm{~cm}$, or $85 \%)$, leaving a final net accumulation of about $10 \mathrm{~cm}$ (Sect. 3.1). The 

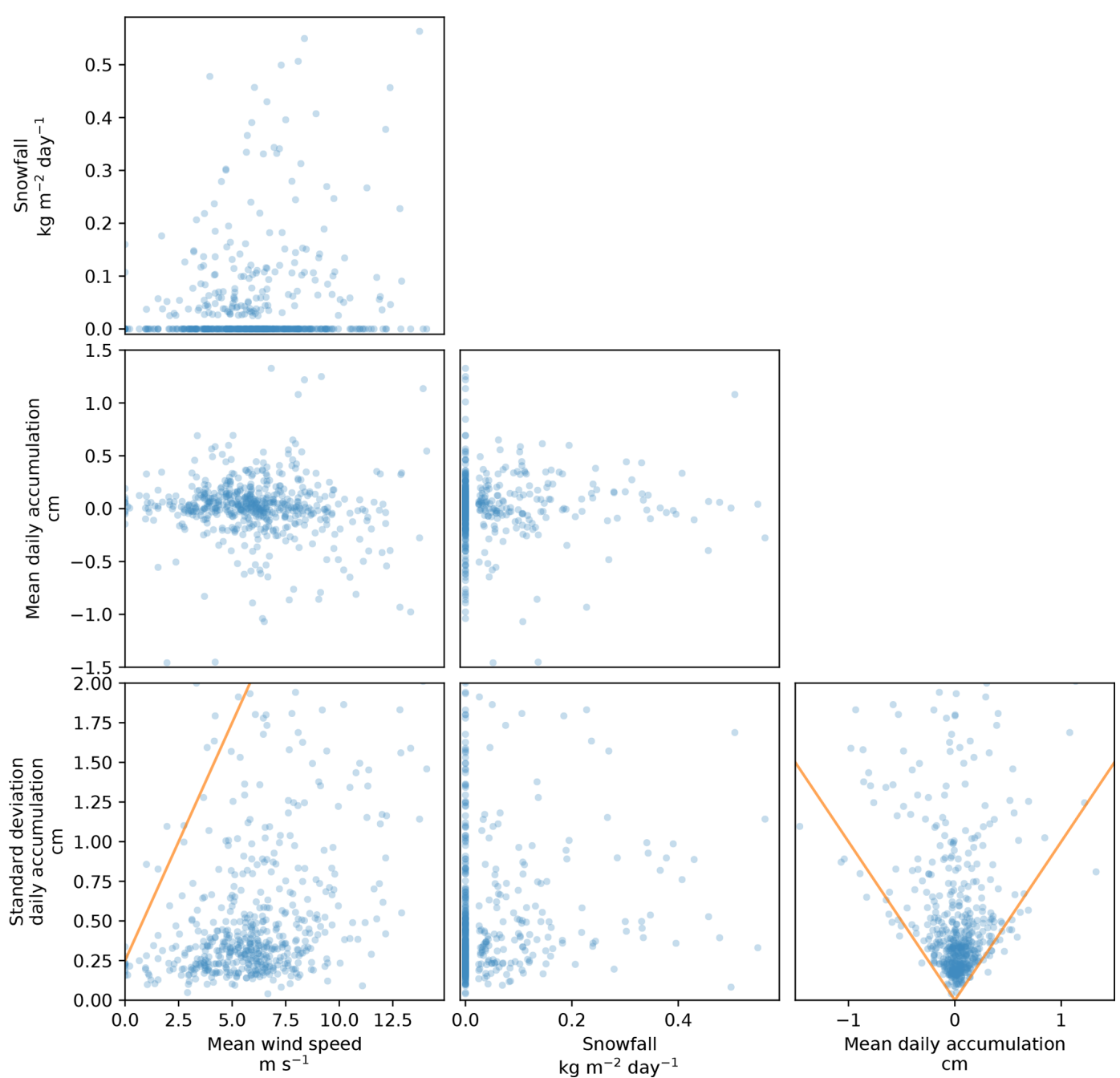

Figure 5. Comparison between mean daily accumulation, standard deviation of daily accumulation, daily snowfall, and mean daily wind speed including data from the 3 years. The orange lines delineate remarkable zones with few data (see Sect. 3.3).

ratio between deposition and net accumulation suggests that a snow particle is remobilized at least $55 / 10=5.5$ times before its definitive settling. This value is to be taken with caution because of the limited frequency of the scans that only allow us to probe the "long-term" deposition-removal cycles, which excludes the rapid rebounds that occur during saltation and blowing snow. We additionally computed the increments above $0.5 \mathrm{~cm}$ (this value is twice as large as the RLS precision). These "significant" events of deposition bring $50 \mathrm{~cm}$ of snow in a year, which is still much larger than the net annual accumulation and again suggests that snow is subject to many deposition-removal cycles. Interestingly, the increments above $2 \mathrm{~cm}$ (call hereinafter "major events" as they each represent more than a fifth of the annual net accumulation) amount to $22 \mathrm{~cm}$, meaning that every pixel receives many times a year at least $2 \mathrm{~cm}$ of snow in a single day (or a few days for the few cases the scanner was not working).
The process of erosion shows similar behavior, with $18.3 \mathrm{~cm}$ removed by events larger than $2 \mathrm{~cm}$ on average over the area.

Overall, the results of this section depict a surface subject to frequent changes that remain invisible to the observers who only access long time-period averages or spatial averages of accumulation. To further explore the accumulation process, in the next section we focus on the major events, which amount to $22 \mathrm{~cm}$.

\subsection{Patchy accumulation}

Figure 7 shows the accumulation map between 4 and 16 July 2015 corresponding to the exceptional event raising the surface by $17 \mathrm{~cm}$ on average and clearly visible in Fig. 3 . We are confident that this is not an artifact because the surface elevation remained affected by this event for months, and the calibration spheres confirm the stability of the setup. Unfortunately, no data are available between 4 and 16 July, 


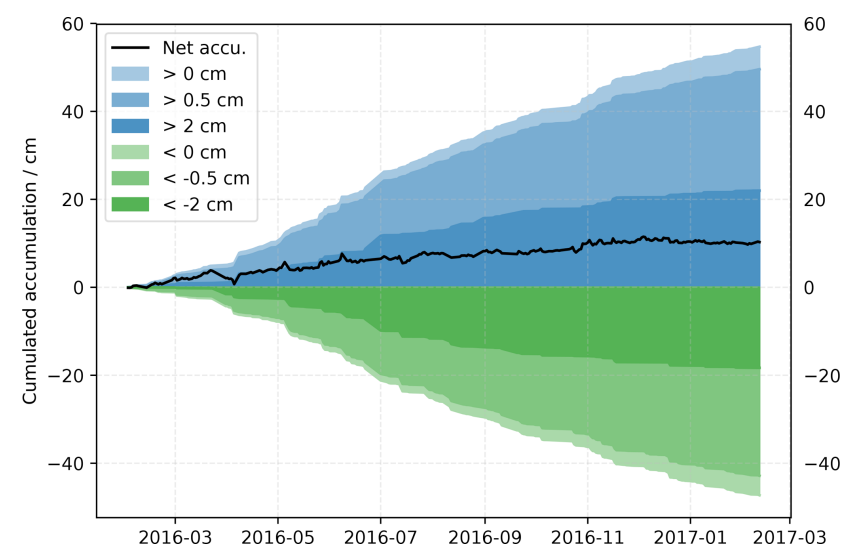

Figure 6. Cumulative spatially averaged amount of snow accumulated (blue $>0$ ) and eroded (green $<0$ ) in every pixel during the period February 2016-February 2017 (period 2a). Only events with accumulation over the threshold 0.5 and $2 \mathrm{~cm}$ and erosion below the thresholds -0.5 and $-2 \mathrm{~cm}$ are taken into account for the lighter blue and green curves. Cumulative net accumulation is shown in black.

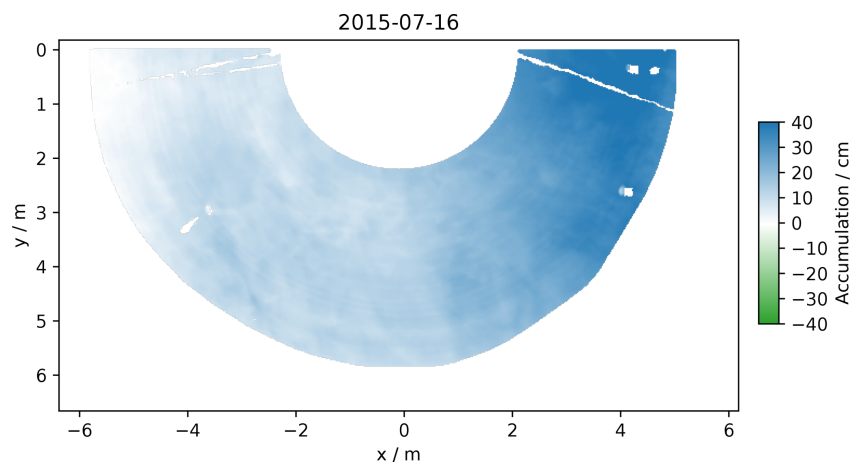

Figure 7. Accumulation between 4 and 16 July 2015.

preventing a precise description of the sequence of this event. This RLS failure was likely caused by snow jamming the lasermeter window, which leads us to suppose that intense snow drift started at the beginning of this period, right after 4 July 2015 . This event is the only one raising the surface as a whole and smoothly. Nonetheless, the accumulation is not even, featuring a trend, with $x$ increasing from nearly $0 \mathrm{~cm}$ (left corner in the figure) to $40 \mathrm{~cm}$ over a distance of about $10 \mathrm{~m}$ (right corner). This corresponds to the decameter-scale dune mentioned above.

In contrast to this rare event, accumulation maps usually look different. This is illustrated by the maps of accumulation between 28 and 29 May 2016 and between 29 and 30 May 2016 (Fig. 8). It is worth noting that the $x$ - and $y$ axis scales and the color scale are different from those in Fig. 7. The first day, the net accumulation is $-0.8 \mathrm{~cm}$, with $80 \%$ of the area in erosion (and $75 \%$ in pronounced ero$\operatorname{sion}(>2 \mathrm{~cm})$ ). The second day, the accumulation is $+0.3 \mathrm{~cm}$ with $62 \%$ of the area in accumulation. In both cases, elon- gated patterns are clearly visible. The second day it is possible to observe that most erosion patterns correspond to the accumulation patterns of the previous day (e.g., the two large blue areas on the left the first day are green the second day), meaning that most of the accumulation features in the first day have been blown away and replaced by new ones with similar shapes (size, elongation, orientation).

To explore the geometrical characteristics of these deposition patterns, that we called patches, we applied a threshold $(2 \mathrm{~cm})$ to the daily accumulation maps and segmented the map. Each individual patch then received a unique label and its geometrical properties were computed using the Python function skimage.measure.regionprops. The properties include area $A$, eccentricity $e$ and major axis length of the best-fitting ellipse ( 0 indicates a circle and 1 an infinitely thin segment), and the orientation of the major axis (with respect to north, increasing eastward). Figure 9 reports the orientation and eccentricity of the elongated patterns only $(e>0.8)$. On 29 May 2016, it is clear that the patches were aligned with orientations ranging from 140 to $192^{\circ}$ with respect to the north. The average orientation is $174^{\circ}$ (we applied weighting proportional to $A e^{2}$ to account for the size and eccentricity). This orientation is nearly south, which unsurprisingly corresponds to mean wind direction of the day $\left(169^{\circ}\right)$ and to the prevailing wind direction (Champollion et al., 2013). The same computation is repeated for the $280 \mathrm{~d}$ of period 2a, yielding 1103 patches that appeared for 93 different days (33\% of the time). As found before for the mean accumulation, there is no clear relationship between the patch properties and wind speed (not shown). The most marked relationship is between the daily-mean orientation and the wind direction on the same day (Fig. 10) with a correlation of 0.33 (the correlation is weighted by the number of patches as in Fig. 10). This simply means that the patches form longitudinal dunes or sastrugi approximatively aligned with the wind direction.

As a consequence of the frequent deposition-removal cycles, many patches studied here are ephemeral. They can be rapidly removed by the next wind event following their formation, as highlighted on the sequence of 29 and 30 May 2016. These ephemeral patches do not contribute to the snowpack in the long term. To capture and investigate more specifically the few patches that remain and settle and that in the end are the important ones for the snow mass balance and the snowpack internal structure, we estimated the time of survival as follows: for each patch detected at time $i$, we compute its initial volume (between the surface at time $i$ and the surface at time $i-1)$ and how this volume evolves at all times $i^{\prime}>i$ (volume between the surface at time $i^{\prime}$ and the surface at time $i-1)$. More precisely we seek the minimum value of this volume and the date at which this minimum is reached. The patch is fully eroded if the minimum volume is $0 \mathrm{~cm}^{3}$ or negative, which happens for 652 of the patches among 1103 detected in period 2a (59\% of the cases). Partial erosion occurs when the minimal volume is between 0 and 


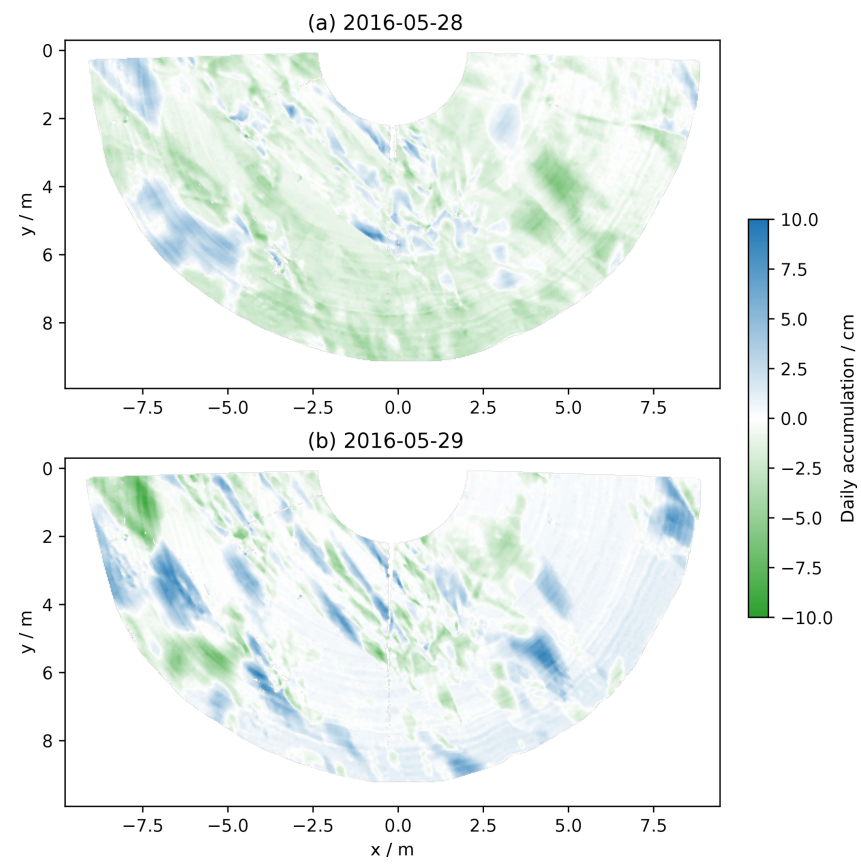

Figure 8. Accumulation between 28 and 29 May 2016 (a) and 29 and 30 May 2016 (b).

the initial volume, which concerns all the other patches. We found none being fully and continuously buried after deposition in our dataset. Full or partial erosion of at least half of a patch volume occurs for a large proportion of them (930, i.e., $84 \%$ ). The mean time of survival before full erosion is $17 \mathrm{~d}$, and for partial erosion this time increases to $46 \mathrm{~d}$, meaning that partial erosion is typically possible after a longer period. In other terms, if a patch is not removed soon after deposition, it is increasingly harder to remove it. The calculation of the time of residence before erosion (Sect. 2.3) provides similar information while not being limited to patches (accumulation over $2 \mathrm{~cm}$ ). The time of residence on the surface before erosion is $15 \mathrm{~d}$ on average over period $2 \mathrm{a}$, with a large spread ( $10 \mathrm{~d}$ standard variation). The maximum is $129 \mathrm{~d}$.

This result confirms that deposition-removal of snow is a very common process and that only a small part of the deposited snow remains on the surface and contributes to the snowpack. Moreover, even when the snow is removed, the number of days spent on the surface can be significant, which lets metamorphism operate and modifies the physical and chemical properties of the snow before it is removed and blown away.

\subsection{Age of the snow on the surface}

We estimate the age of the snow on the surface with the algorithm described in Sect. 2.3 for all the scans. Figures 11 and 12 show the age of snow near the end of period 2a (18 and 27 January 2017) with respect to the beginning. We have chosen these dates because they are less affected by the fault

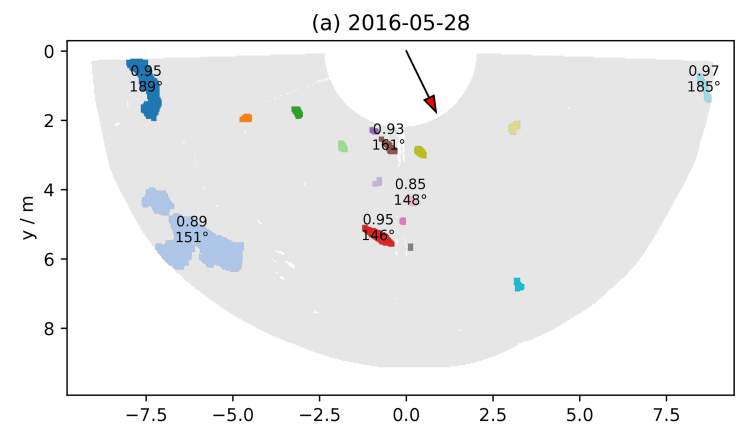

(b) 2016-05-29

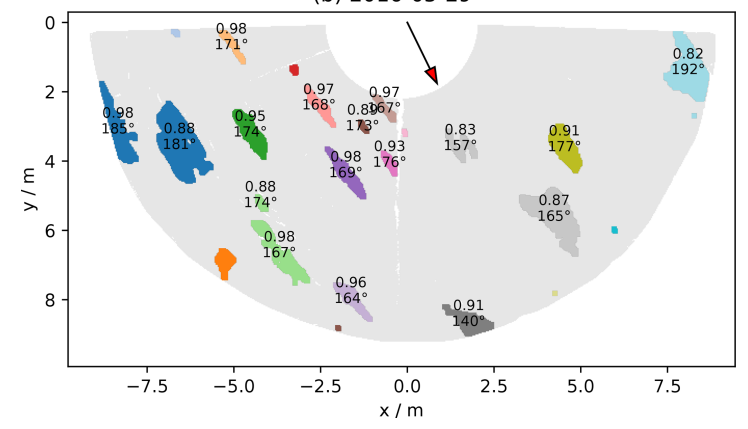

Figure 9. Patches of accumulation $(>2 \mathrm{~cm}$ ) between 28 and 29 May 2016 (a) and 29 and 30 May 2016 (b). For each patch with sufficient elongation, the circularity and the orientation are indicated. The southern direction $\left(180^{\circ}\right)$ is indicated by the red arrow.

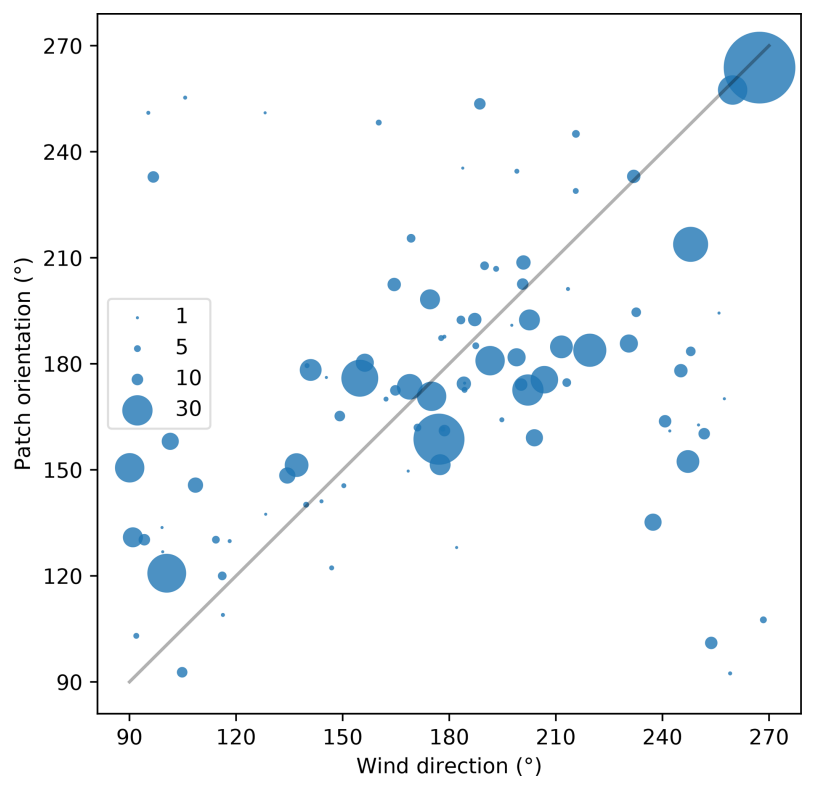

Figure 10. Daily-mean orientation of the accumulation patches as a function of the daily-mean wind speed. The size of the symbols indicates the number of patches.

that increasingly affected RLS from February 2017. To highlight the sensitivity of the algorithmic choices, the histogram in Fig. 12 shows as white dotted bars the result of processing 


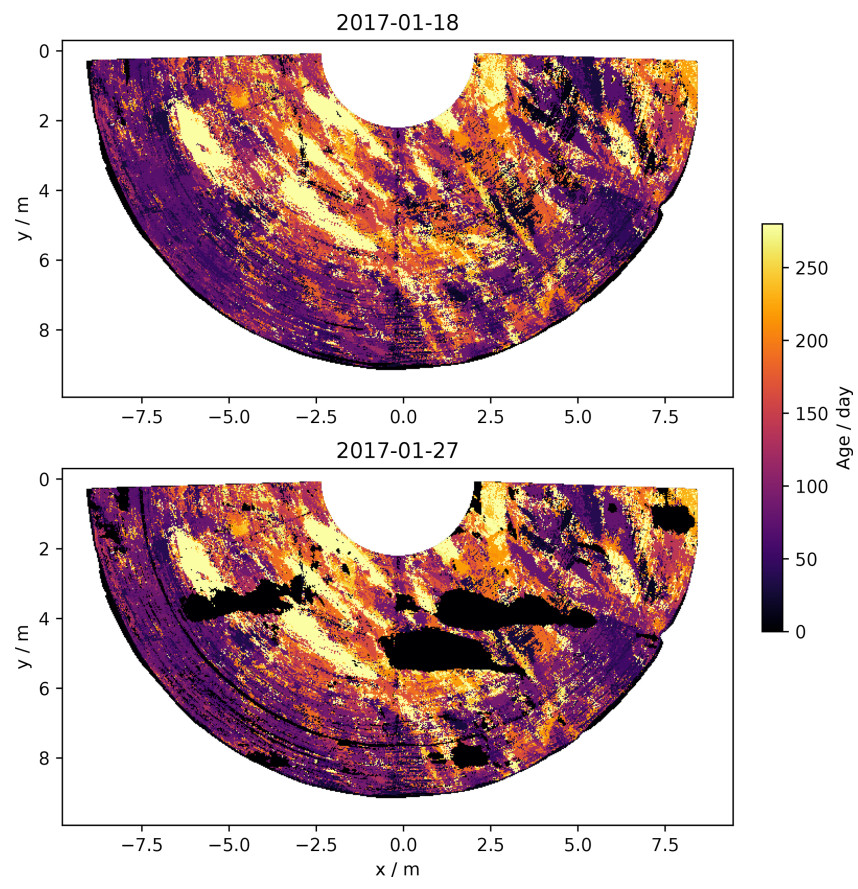

Figure 11. Map of age of the snow on the surface for two dates.

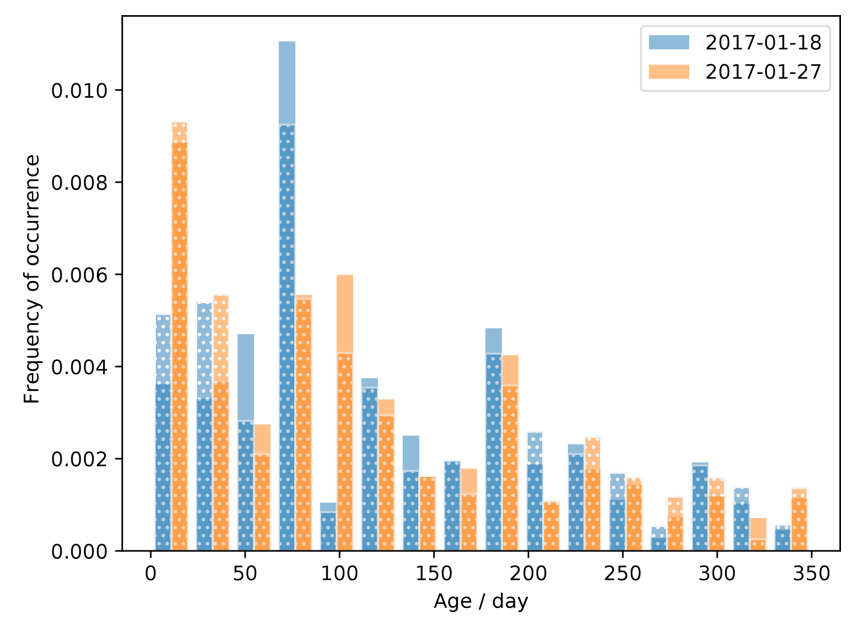

Figure 12. Distribution of the age of the snow on the surface for two dates (blue and orange). The age is determined using the algorithm described in Sect. 2.3 based on the accumulation and erosion thresholds $\delta_{\mathrm{a}}=1 \mathrm{~cm}$ and $\delta_{\mathrm{e}}=0 \mathrm{~cm}$ (solid colored bars) and $\delta_{\mathrm{a}}=0.5 \mathrm{~cm}$ and $\delta_{\mathrm{e}}=-0.5 \mathrm{~cm}$ (white dotted bars).

the scans with symmetrical thresholds for accumulation and erosion.

The map and the distribution of age show that snow with very different ages is present on the surface, from 0 (accumulation of the day) to the maximum possible given the duration of the time series. About $48 \%$ of the surface is younger than $100 \mathrm{~d}$ (which is thus the approximate median age), while about $24 \%$ is older than $200 \mathrm{~d}$ and $10 \%$ older than $300 \mathrm{~d}$. These figures are moderately affected when using the al- gorithm with the symmetrical thresholds $(46 \%, 30 \%$, and $14 \%$, respectively).

These proportions also change from day to day because of the ephemeral deposition-erosion as illustrated on 27 January 2017 (Fig. 11) where a few patches of recent accumulation covered $11 \%$ of the surface. These patches disappeared the day after (data not shown), forming the surface as shown in the 18 January map. It is also clear from the histograms that almost all ages are present at the same time, which is in agreement with the apparent regularity of the accumulation (Fig. 4).

Note that period $2 \mathrm{a}$ had a relatively high net accumulation and narrow spatial distribution of accumulation, so it is likely that the distribution of age shown here could be wider for years with less accumulation.

The age maps provide another interesting piece of information. We can indeed see clear patterns with marked alignments on these maps (Fig. 11). This confirms the patchy nature of the accumulation process already noted in the previous section (Sect. 3.4). We indeed showed that a significant part of the daily accumulation over $2 \mathrm{~cm}$ is organized in patches but that most of them $(59 \%)$ do not contribute at all in the long term to the surface mass balance. Here, we complement this by showing that some of the partially eroded patches remain clearly visible on the surface even after a year.

\subsection{Structure of the snowpack}

The accumulation process depicted in the previous section may affect the internal structure of the snowpack and its spatial variability. The burial of the snow can be tracked using the RLS, at least over a short depth given the limited length of the time series. Figure 13 shows the snowpack internal structure along the $x$-axis transect at $y=4 \mathrm{~m}$ (see, e.g., Fig. 11) at the end of period $2 \mathrm{a}$. It is obtained, assuming no compaction, by plotting the successive positive increments of surface elevation at each point with a color depending on the date of deposition. The gray color marks snow older than the first day of period $2 \mathrm{a}$ (1 February 2016). The $z$ origin corresponds to the mean elevation in the whole scanned area at the beginning of period 1 . The two gray lines represent the mean at the beginning and end of period $2 \mathrm{a}$, respectively.

It is remarkable that the figure shows distinct coherent patterns and fairly little noise. The figure confirms that the heterogeneity on the surface transfers into the snowpack. For instance, around $x=0 \mathrm{~m}$ old snow is present at $11 \mathrm{~cm}$ under the surface (yellow) whilst the surface is young (black). This area presents the greatest diversity in terms of age and the largest number of distinct layers. Around $x=-3 \mathrm{~m}$ in contrast, the whole accessible depth features a single homogeneous layer formed in March 2016 (orange). Another thick homogeneous layer is found around $x=-7.5 \mathrm{~m}$ but it is much younger (violet, August 2016). Even where we do not observe a unique layer, it is clear that only a few events 


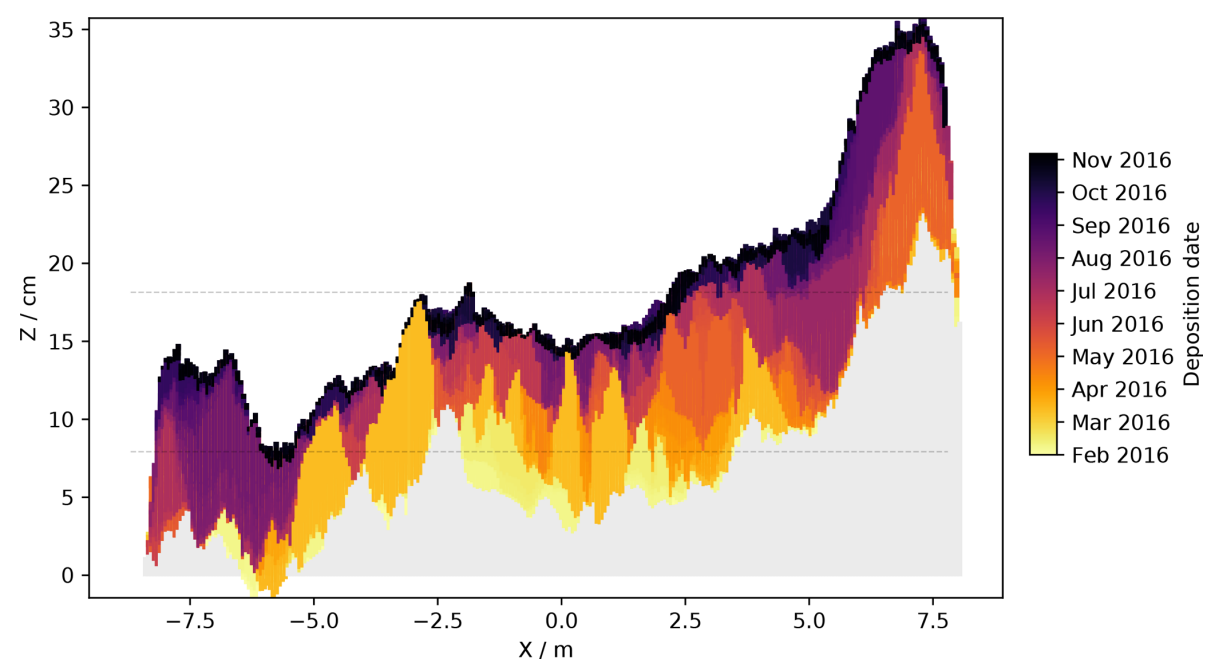

Figure 13. Snowpack internal structure along the transect parallel to the $x$ axis at $Y=4 \mathrm{~m}$ deduced over the period February 2016February 2017 (period 2a). The color indicates the date of deposition of the layer. The gray shade corresponds to snow older than the first acquisition of RLS in this period. The two gray lines represent the scanned-area average surface elevation at the beginning and end of period 2a.

$(\approx 5)$ have contributed to the snowpack, forming a few distinct layers. Conversely, it means that at every point many deposition events occurring during a year are not represented, which implies that the profiles of snow physical and chemical properties are probably very different from one point to another.

Another remarkable feature is around $x=7.5 \mathrm{~m}$ where we can see a $10 \mathrm{~cm}$ high dune deposited in July 2016 (orange) where the surface was already higher than the surroundings as marked by the gray lines. Then, two successive events (in September and November, violet) accumulated more snow on the sides of this dune, which was then about $15 \mathrm{~cm}$ higher than the surrounding surface. This may be the result of interaction with the pre-existing dune leading to preferential deposition on one side, here the windward side. A similar behavior is observed around $x=-4 \mathrm{~m}$ where the space between the two small dunes (in light orange) has been filled by some subsequent events.

\section{Discussion}

The laser scanner that was operating at Dome $\mathrm{C}$ for about 3 years provides very rich and new information on the accumulation process. We analyze these results successively from a temporal, spatial, and snowpack perspective.

\subsection{Temporal perspective}

The RLS provides contrasted results regarding the surface evolution depending on the spatial scale of interest. On the one hand, the time series of surface elevation averaged over the whole scanned area depicts a slow and relatively regu- lar accumulation, without seasonality or rapid events, except a single event which raised the surface by $8 \mathrm{~cm}$ in a few days during the first winter of observation. The accumulation rate measured by RLS ranges between 8 and $10 \mathrm{~cm} \mathrm{yr}^{-1}$ for the 3 years of observation, which agrees with values reported by previous studies for Dome C (e.g., Petit et al., 1982; Urbini et al., 2008). The time series of rms height (standard deviation of the surface elevation) is also relatively steady, which again suggests that only slow changes occur over the scanned area. This overall stability is further illustrated in the sequence of photographs in Fig. 14. The photographs were taken from $20 \mathrm{~m}$ above ground at Dome C. They depict a landscape dominated by barchan dunes with few differences between the pictures of January and December 2017, 11 months apart. This steadiness is surprising because the accumulation over this period has been of the order of $8 \mathrm{~cm}$, the typical annual accumulation expected in the area (Petit et al., 1982; Genthon et al., 2015).

On the other hand, a very different picture is obtained by investigating the daily changes in surface elevation (i.e., the daily accumulation) and the small spatial scales. Indeed, many local changes in elevation affect the surface almost everyday. Most of these changes are however ephemeral (a few tens of days) so that the overall statistics of the surface are relatively constant or slowly changing. These changes are typically caused by migrating patches on their way downwind or remobilization of loose snow deposited by a recent storm. The picture of September 2017 in Fig. 14 illustrates how major these ephemeral changes in the landscape can be. Nevertheless, these temporarily accumulated snow masses have little consequence as far as the surface mass balance and the snowpack internal structure are concerned. However, they do have consequences on other aspects as they shield 

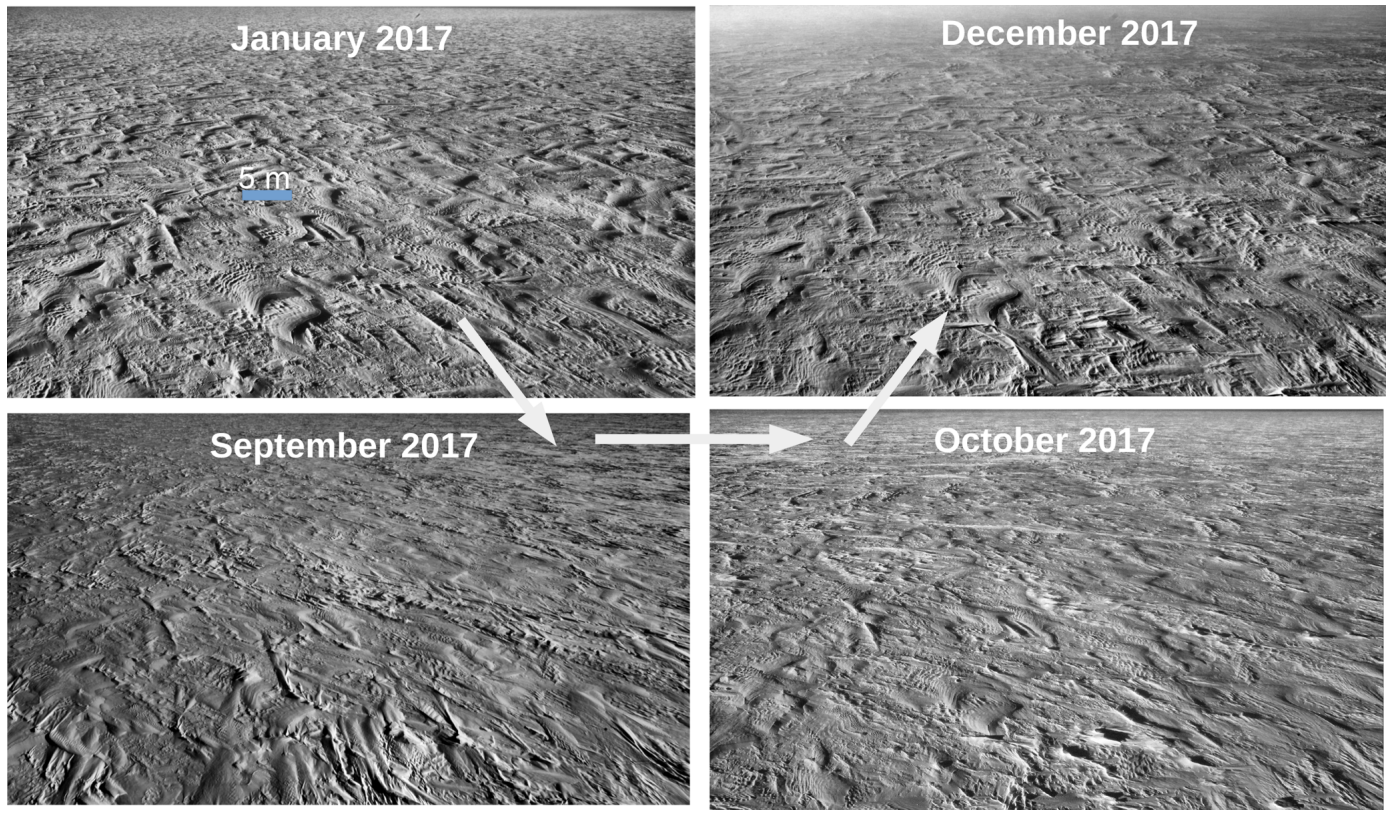

Figure 14. Photographs in the near infrared range $(820 \mathrm{~nm})$ taken from $20 \mathrm{~m}$ height at Dome $\mathrm{C}\left(75^{\circ} \mathrm{S}, 123^{\circ} \mathrm{E}\right)$ in $\mathrm{Antarctica}$ on $27 \mathrm{Jan}-$ uary 2017 (21:00 UTC), 21 September 2017 (06:00 UTC), 23 October 2017 (20:00 UTC), and 4 December 2017 (17:00 UTC) and highlighting how little the surface can have changed over nearly 1 year.

the snow surface for a few days, weeks, or even months from solar and infrared radiation and suppress the photochemistry activity and the exchanges of heat, water, and chemical components between the consolidated surface and the atmosphere. During the period of residence, these ephemeral snow masses are subject to transformations resulting in changes in their physical, isotopic, and chemical properties (Casado et al., 2018). When these masses are transported in a downwind region and deposited, they can be very different compared to fresh snow coming from direct local snowfall. This phenomenon of deposition-erosion-transport repeats itself several times. We provide a rough estimate of about five cycles before settling, considering only the timescales longer than a day, thus excluding the many rebounds occurring during saltation. We are however unable to estimate the distance traveled over these cycles.

The meteorological conditions triggering the surface changes raise an important question for modeling, but have not been elucidated here. Snowfalls seem to be frequent at Dome $\mathrm{C}$ according to the ERA-I reanalysis, which is in agreement with the slow and regular accumulation observed with RLS, but these events are not related to the observed changes in the surface. The occurrence of snowfalls in ERA-I has been compared to satellite data (Palerme et al., 2014; Lemonnier et al., 2018) in a coastal region and found to be reliable, but conversely it is well known that ERAI misses a large part of the accumulation amount around Dome C (Genthon et al., 2015). Apart from snowfall, common sense suggests that wind speed should be a driver of change. Groot Zwaaftink et al. (2013) considered in a modeling study that snow deposition occurred after sustained wind over $3 \mathrm{~m} \mathrm{~s}^{-1}$ for $100 \mathrm{~h}$. Libois et al. (2014) similarly considered that wind speed over $7 \mathrm{~m} \mathrm{~s}^{-1}$ is required to initiate drift, which then continues as long as this speed limit is reached at least once within $24 \mathrm{~h}$. This criterion yields a drift rate of 70 events per year, which compares well with our estimates of $93 \mathrm{~d}$ with patch formation over a year. Nevertheless, our analysis has not revealed any robust simple relationship with the wind speed. The accuracy of the daily accumulation derived from RLS is limited by noise and some artifacts, which could be an explanation. However, a complex interaction between wind and the surface is also not to be excluded. For instance, wind with a direction perpendicular to the prevailing surface roughness exerts a stronger drag on the surface than when parallel, potentially resulting in stronger erosion. This effect was at least once shown on the removal of surface hoar at Dome C (Champollion et al., 2013). Similarly Amory et al. (2017) showed how drag decreased during a snowfall episode (though not at Dome $\mathrm{C}$, but in a coastal region) and (Amory et al., 2016) how the surface roughness direction adjusted to the wind direction. Another key parameter, missing here in our analysis, is the cohesion of the snow (Sommer et al., 2017) that is able to modulate to a very large extent the snow mobility (Vionnet et al., 2012).

\subsection{Spatial perspective}

All our results show great variability at the meter scale on the surface (e.g., daily accumulation, age of snow on the sur- 
face) and within the snowpack (snow layers). Most of this variability results from the heterogeneous accumulation of snow and the selective erosion. We propose calling this former process "patchy" accumulation, in contrast to the even accumulation "in layers", which is typical of the alpine regions. Representing this process in one-dimensional snow models is a challenge. Groot Zwaaftink et al. (2013) managed to represent the fact that most patches are ephemeral by summing snowfalls and delaying the effective deposition based on wind-speed-based criteria as aforementioned. Even though this results in thicker deposition per event than when all snowfalls are deposited independently, it is impossible with one-dimensional models to account for the fact that the patches often cover a very small fraction of the surface and therefore can be much thicker than if a snowfall is evenly deposited. This is fundamental to produce layer thickness of a few centimeters, as observed in the field, when most snowfalls bring less than a millimeter per day (e.g., $4 \mathrm{~mm}$ is the maximum of snow over the 3-year period in ERA-I). Only using a distributed or three-dimensional approach enables the representation of this feature. The attempts of Libois et al. (2014) (already mentioned) were a relative success with a good representation of the spatial distribution of annual accumulation compared to the GLACIOCLIM stake network. However, some of their hypotheses need to be reevaluated in light of our new results. For instance, they assumed that snow deposition only occurs in the lowest $20 \%$ of the surface. This tends to smooth the surface, yet we have shown an example of accumulation near the highest dunes, which conversely tends to enhance the spatial variability. This may be the reason why they obtained an underestimation of the variability of the density and specific surface area profiles in the snowpack. Further work is needed to implement a process able to produce dunes and more generally to transfer the observational findings of the present study to concrete processing, adequate for numerical modeling.

It results from the patchy accumulation and the strong erosion that the surface is continuously rough at Dome $\mathrm{C}$, as evidenced by the rms height. This is usually not the case in alpine regions where roughness increases after snowfalls (Naaim-Bouvet et al., 2016). Surface roughness can amplify itself because it plays the role of an aerodynamic obstacle that promotes heterogeneous deposition and the formation of new rough features overlying the old ones. Moreover, in the longer term, snow on the different faces of the roughness features is exposed to different radiation and wind shear conditions, likely leading to different evolutions of the microstructure (different sintering, sublimation, deposition, and metamorphism). The RLS is limited on this aspect. An avenue is to exploit the laser backscatter signal available from some lasermeters, to retrieve the specific surface area, microroughness (hoar), cohesion, and potentially other properties.

It is also worth mentioning that the patches studied throughout this paper are smaller in general than the accumulation pattern that appeared in 4-16 July 2015 (Fig. 7). The

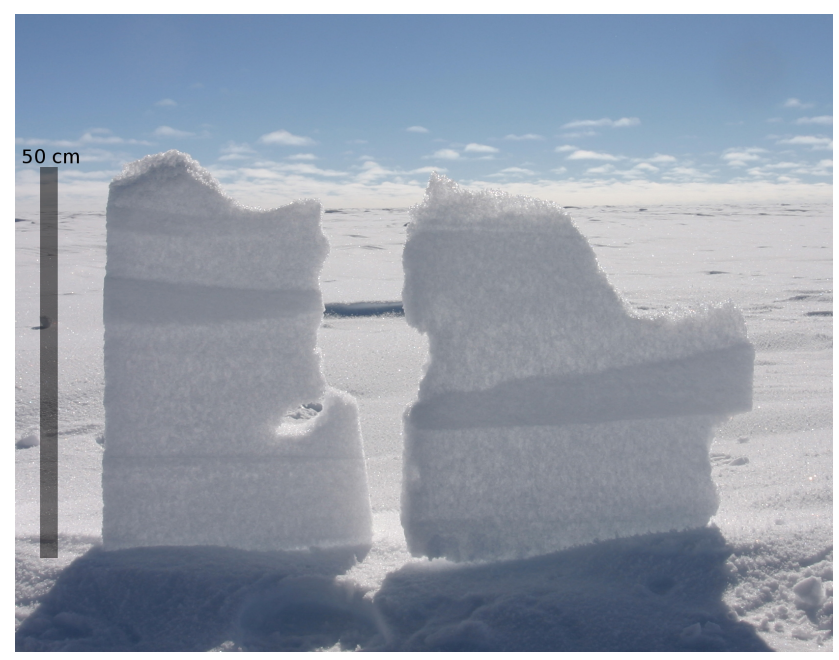

Figure 15. Photograph of a thin vertical section extracted from $5 \mathrm{~m}$ depth at Dome C in January 2010 showing the persistence of heterogeneity at depth.

latter is probably more similar to the barchan dunes visible in the photographs in Fig. 14 and evoked in Picard et al. (2014) and Sommer et al. (2018). These dunes have tails elongated at $\approx 45^{\circ}$ with respect to the wind direction (Filhol and Sturm, 2015) while the small patches are well aligned with the wind direction (longitudinal bedform). These are clearly different objects, with different sizes (meter versus decameter) and different dynamics (daily versus yearly).

\subsection{Snowpack perspective}

The heterogeneity of the surface eventually transfers to the snowpack in depth. Figure 15 shows a vertical section of snow extracted from a depth of $5 \mathrm{~m}$ with evidence of past windpacks. Several layers appear distinctively despite the age (over 50 years old). It is not excluded that transformations of the snow after burial may have amplified the initial differences of snow properties, but in any case, these layers are thick, and were certainly thick when deposited, compared to the annual accumulation. These layers are maybe even thicker than most patches identified with RLS or in the snowpack reconstruction (Fig. 13). An important consequence of this internal heterogeneity concerns the interpretation of ice cores at high resolution or measurements along profiles. With the patchy accumulation and with snow age on the surface spanning at least 1 year, it is clear that some precipitation events, volcanic eruptions, or nuclear events may not be recorded everywhere, at least not with the same intensity and depending on the duration of the events and the mode of deposition (dry or wet). Gautier et al. (2016) explored this aspect in detail for volcano traces using five cores extracted $1 \mathrm{~m}$ apart at Dome C. They found that volcanic events were missing in $30 \%$ of the cores on average and that the flux uncertainty reached $65 \%$ when a single core was used. Our 
dataset is however insufficient to make a precise comparison with these statistics because the presence of a tracer in a snow patch depends on the date of first precipitation of that patch, which is unknown, and we can only estimate the date of its last deposition. Moreover, considering that erosion occurs for $15 \mathrm{~d}$ on average (and up to $129 \mathrm{~d}$ ) after deposition and that snow can be remobilized several times, a patch is composed of snow precipitated over a time window of days to potentially years before settling. This should tend to homogenize the presence of a tracer.

Another issue is the variable age of the snow at a given depth. We showed variations up to 1 year, but it was likely underestimated due to the limited duration of our time series. This age spread not only hinders the analysis of any annual and sub-annual signals, but also may explain some apparent multi-year signals as discussed by Laepple et al. (2018). This also suggests that depth synchronization should be applied between different cores. Gautier et al. (2016) found a maximal offset of $40 \mathrm{~cm}$ between two of their five cores, which is the high end of what can be explained with our estimates of rms height (up to $8 \mathrm{~cm}$ ) or annual accumulation range (up to $30 \mathrm{~cm}$ ).

\section{Conclusions}

The laser scan dataset collected at Dome $\mathrm{C}$ over 3 years provides, for the first time, quantitative information on the snow surface dynamics at a site typical of the ridge area on the East Antarctic Plateau. The main results demonstrate that (i) the surface elevation increases on average with an apparent regularity, without seasonality; (ii) the variations at meter scales are in contrast large and highly dynamical; (iii) the surface is continuously rough, with a rms height of up to $8 \mathrm{~cm}$; (iv) the accumulation and erosion events are frequent, spatially uneven and significant with respect to the annual net accumulation which implies that snow is remobilized several times before settling; (v) the age distribution of snow on the surface spans over more than a year; and (vi) the snowpack internal structure reflects the surface heterogeneity. These results are useful and have significant consequences for several research topics including surface mass balance, surface energy budget, and thus climate, photochemistry, snowpack evolution, and signals archived in ice cores, which require further work. We also plan to improve the RLS to capture smaller timescales (hourly) and attempt to increase its robustness in order to collect longer time series as this proved to be important to assess the age of surface snow and capture the interannual climate variability. The present results can also be exploited to build stochastic or physical models of the accumulation and erosion processes. Investigating other locations on the Antarctic plateau, with different annual accumulation and wind speed, is necessary.
Code and data availability. The RLS dataset is available from https://doi.org/10.18709/perscido.2019.07.ds249 (Picard et al., 2019).

Author contributions. LA and GP developed the Rugged LaserScan (RLS), which was deployed and maintained by EL at Dome C. RC conducted a first analysis during his master thesis, under the supervision of GP, LA, and ML. The analysis was extended by GP. All authors contributed to the paper.

Competing interests. The authors declare that they have no conflict of interest.

Acknowledgements. The RLS was developed under the ANR MONISNOW program and OSUG@2020 Labex grant. The authors acknowledge the French Polar Institute (IPEV) for the financial and logistic support at Concordia station in Antarctica through the NIVO program. We acknowledge Vincent Favier for providing the GLACIOCLIM stake network observations. In situ metereological data and information were obtained from the IPEV/PNRA project "Routin Meteorological Observation at Station Concordia" - http://www.climantartide.it (last access: 15 July 2019). We would also like to thank the two anonymous reviewers, as well as Florent Domine and Charles Amory for their very helpful comments.

Financial support. This research has been supported by the Agence Nationale de la Recherche (grant no. 1-JS56-005-01 MONISNOW) and the Agence Nationale de la Recherche (grant no. ANR10 LABX56).

Review statement. This paper was edited by Martin Schneebeli and reviewed by two anonymous referees.

\section{References}

Adodo, F. I., Remy, F., and Picard, G.: Seasonal variations of the backscattering coefficient measured by radar altimeters over the Antarctic Ice Sheet, The Cryosphere, 12, 1767-1778, https://doi.org/10.5194/tc-12-1767-2018, 2018.

Agosta, C., Amory, C., Kittel, C., Orsi, A., Favier, V., Gallée, H., van den Broeke, M. R., Lenaerts, J. T. M., van Wessem, J. M., van de Berg, W. J., and Fettweis, X.: Estimation of the Antarctic surface mass balance using the regional climate model MAR (19792015) and identification of dominant processes, The Cryosphere, 13, 281-296, https://doi.org/10.5194/tc-13-281-2019, 2019.

Amory, C., Naaim-Bouvet, F., Gallée, H., and Vignon, E.: Brief communication: Two well-marked cases of aerodynamic adjustment of sastrugi, The Cryosphere, 10, 743-750, https://doi.org/10.5194/tc-10-743-2016, 2016.

Amory, C., Gallée, H., Naaim-Bouvet, F., Favier, V., Vignon, E., Picard, G., Trouvilliez, A., Piard, L., Genthon, C., and Bellot, H.: Seasonal Variations in Drag Coefficient over a Sastrugi- 
Covered Snowfield in Coastal East Antarctica, Bound.-Lay. Meteorol., 164, 107-133, https://doi.org/10.1007/s10546-017-02425, 2017.

Arthern, R. J., Winebrenner, D. P., and Vaughan, D. G.: Antarctic snow accumulation mapped using polarization of $4.3-\mathrm{cm}$ wavelength microwave emission, J. Geophys. Res., 111, D06107, https://doi.org/10.1029/2004JD005667, 2006.

Bromwich, D. H., Nicolas, J. P., and Monaghan, A. J.: An Assessment of Precipitation Changes over Antarctica and the Southern Ocean since 1989 in Contemporary Global Reanalyses, J. Climate, 24, 4189-4209, https://doi.org/10.1175/2011jcli4074.1, 2011.

Casado, M., Landais, A., Picard, G., Münch, T., Laepple, T., Stenni, B., Dreossi, G., Ekaykin, A., Arnaud, L., Genthon, C., Touzeau, A., Masson-Delmotte, V., and Jouzel, J.: Archival processes of the water stable isotope signal in East Antarctic ice cores, The Cryosphere, 12, 1745-1766, https://doi.org/10.5194/tc-12-17452018, 2018.

Champollion, N., Picard, G., Arnaud, L., Lefebvre, E., and Fily, M.: Hoar crystal development and disappearance at Dome C, Antarctica: observation by near-infrared photography and passive microwave satellite, The Cryosphere, 7, 1247-1262, https://doi.org/10.5194/tc-7-1247-2013, 2013.

Dee, D. P., Uppala, S. M., Simmons, A. J., Berrisford, P., Poli, P., Kobayashi, S., Rae, U., Balmaseda, M. A., Balsamo, G., Bauer, P., Bechtold, P., Beljaars, A. C. M., van de Berg,L., Bidlot, J., Bormann, N., Delsol, C., Dragani, R., Fuentes, M., Geer, A. J., Haimberger, L., Healy, S. B., Hersbach, H., Hólm, E. V., Isaksen, L., Kållberg, P., Köhler, M., Matricardi, M., McNally, A. P., Monge-Sanz, B. M., Morcrette, J.-J., Park, B.-K., Peubey, C., de Rosnay, P., Tavolato, C., Thépaut, J.-N., and Vitart, F.: The ERAInterim reanalysis: configuration and performance of the data assimilation system, Q. J. Roy. Meteor. Soc., 137, 553-597, https://doi.org/10.1002/qj.828, 2011.

Déry, S. J. and Yau, M. K.: Large-scale mass balance effects of blowing snow and surface sublimation, J. Geophys. Res.-Atmos., 107, ACL 8-1-ACL 8-17, https://doi.org/10.1029/2001jd001251, 2002.

Favier, V., Agosta, C., Parouty, S., Durand, G., Delaygue, G., Gallée, H., Drouet, A.-S., Trouvilliez, A., and Krinner, G.: An updated and quality controlled surface mass balance dataset for Antarctica, The Cryosphere, 7, 583-597, https://doi.org/10.5194/tc-7-583-2013, 2013.

Filhol, S. and Sturm, M.: Snow bedforms: A review, new data, and a formation model, J. Geophys. Res.-Earth., 120, 1645-1669, https://doi.org/10.1002/2015jf003529, 2015.

Frezzotti, M., Gandolfi, S., La Marca, F., and Urbini, S.: Snow dunes and glazed surfaces in Antarctica: new field and remotesensing data, Ann. Glaciol., 34, 81-88, 2002.

Furukawa, T., Kamiyama, K., and Station, M. H.: Snow surface features along the traverse route from the coast to Dome Fuji and Queen Maud Land and Antarctica, in: Proc NIPR Symp Polar Meteorol Glaciol., 10, 13-24, 1996.

Gallée, H., Guyomarc'h, G., and Brun, E.: Impact of snow drift on the Antarctic ice sheet surface mass balance: possible sensitivity to snow-surface properties, Bound.-Lay. Meteorol., 99, 1-19, https://doi.org/10.1023/A:1018776422809, 2001.

Gallet, J.-C., Domine, F., Savarino, J., Dumont, M., and Brun, E.: The growth of sublimation crystals and surface hoar on the Antarctic plateau, The Cryosphere, 8, 1205-1215, https://doi.org/10.5194/tc-8-1205-2014, 2014.

Gautier, E., Savarino, J., Erbland, J., Lanciki, A., and Possenti, P.: Variability of sulfate signal in ice core records based on five replicate cores, Clim. Past, 12, 103-113, https://doi.org/10.5194/cp12-103-2016, 2016.

Genthon, C., Six, D., Scarchilli, C., Ciardini, V., and Frezzotti, M.: Meteorological and snow accumulation gradients across Dome C, East Antarctic plateau, Int. J. Climatol., 36, 455-466, https://doi.org/10.1002/joc.4362, 2015.

Gow, A. J.: On the rates of growth of grains and crystals in south polar firn, J. Glaciol., 8, 241-252, 1969.

Grazioli, J., Genthon, C., Boudevillain, B., Duran-Alarcon, C., Del Guasta, M., Madeleine, J.-B., and Berne, A.: Measurements of precipitation in Dumont d'Urville, Adélie Land, East Antarctica, The Cryosphere, 11, 1797-1811, https://doi.org/10.5194/tc-111797-2017, 2017.

Groot Zwaaftink, C. D., Cagnati, A., Crepaz, A., Fierz, C., Macelloni, G., Valt, M., and Lehning, M.: Event-driven deposition of snow on the Antarctic Plateau: analyzing field measurements with SNOWPACK, The Cryosphere, 7, 333-347, https://doi.org/10.5194/tc-7-333-2013, 2013.

Kochanski, K., Anderson, R. S., and Tucker, G. E.: Statistical Classification of Self-Organized Snow Surfaces, Geophys. Res. Lett., 39, 6532-6541, https://doi.org/10.1029/2018g1077616, 2018.

Krinner, G., Magand, O., Simmonds, I., Genthon, C., and Dufresne, J. L.: Simulated Antarctic precipitation and surface mass balance at the end of the twentieth and twenty-first centuries, Clim. Dynam., 28, 215-230, https://doi.org/10.1007/s00382-006-0177-x, 2006.

Laepple, T., Münch, T., Casado, M., Hoerhold, M., Landais, A., and Kipfstuhl, S.: On the similarity and apparent cycles of isotopic variations in East Antarctic snow pits, The Cryosphere, 12, 169187, https://doi.org/10.5194/tc-12-169-2018, 2018.

Leduc-Leballeur, M., Picard, G., Macelloni, G., Arnaud, L., Brogioni, M., Mialon, A., and Kerr, Y.: Influence of snow surface properties on L-band brightness temperature at Dome C, Antarctica, Remote Sens. Environ., 199, 427-436, https://doi.org/10.1016/j.rse.2017.07.035, 2017.

Lehning, M., Bartelt, P., Brown, B., Russi, T., Stöckli, U., and Zimmerli, M.: SNOWPACK model calculations for avalanche warning based upon a new network of weather and snow stations, Cold Reg. Sci. Technol., 30, 145-157, 1999.

Lemonnier, F., Madeleine, J.-B., Claud, C., Genthon, C., DuránAlarcón, C., Palerme, C., Berne, A., Souverijns, N., van Lipzig, N., Gorodetskaya, I. V., L'Ecuyer, T., and Wood, N.: Evaluation of CloudSat snowfall rate profiles by a comparison with in situ micro-rain radar observations in East Antarctica, The Cryosphere, 13, 943-954, https://doi.org/10.5194/tc13-943-2019, 2019.

Lenaerts, J. T. M., van den Broeke, M. R., Déry, S. J., KönigLanglo, G., Ettema, J., and Munneke, P. K.: Modelling snowdrift sublimation on an Antarctic ice shelf, The Cryosphere, 4, 179_ 190, https://doi.org/10.5194/tc-4-179-2010, 2010.

Lenaerts, J. T. M., van den Broeke, M. R., van de Berg, W. J., van Meijgaard, E., and Munneke, P. K.: A new, high-resolution surface mass balance map of Antarctica (1979-2010) based on regional atmospheric climate modeling, Geophys. Res. Lett., 39, L04501, https://doi.org/10.1029/2011g1050713, 2012. 
Libois, Q., Picard, G., Arnaud, L., Morin, S., and Brun, E.: Modeling the impact of snow drift on the decameterscale variability of snow properties on the Antarctic Plateau, J. Geophys. Res.-Atmos., 119, 11662-11681, https://doi.org/10.1002/2014jd022361, 2014.

Naaim-Bouvet, F., Picard, G., Bellot, H., Arnaud, L., and Vionnet, V.: Snow surfaec roughness monitoring using time-lapse terrestrial laserscan, in: Proceedings, International Snow Science Workshop, Breckenridge, Colorado, 2016.

Palerme, C., Kay, J. E., Genthon, C., L'Ecuyer, T., Wood, N. B., and Claud, C.: How much snow falls on the Antarctic ice sheet?, The Cryosphere, 8, 1577-1587, https://doi.org/10.5194/tc-8-15772014, 2014.

Petit, J. R., Jouzel, J., Pourchet, M., and Merlivat, L.: A detailed study of snow accumulation and stable isotope content in Dome C (Antarctica), J. Geophys. Res., 87, 4301, https://doi.org/10.1029/jc087ic06p04301, 1982.

Picard, G., Royer, A., Arnaud, L., and Fily, M.: Influence of meter-scale wind-formed features on the variability of the microwave brightness temperature around Dome $\mathrm{C}$ in Antarctica, The Cryosphere, 8, 1105-1119, https://doi.org/10.5194/tc8-1105-2014, 2014.

Picard, G., Arnaud, L., Panel, J.-M., and Morin, S.: Design of a scanning laser meter for monitoring the spatio-temporal evolution of snow depth and its application in the Alps and in Antarctica, The Cryosphere, 10, 1495-1511, https://doi.org/10.5194/tc10-1495-2016, 2016.

Picard, G., Arnaud, L., and Lefebvre, E.: Timeseries of surface elevation maps at Dome $\mathrm{C}$ measured by time lapse laserscanning, Data set, Perscido-Grenoble-Alpes, https://doi.org/10.18709/perscido.2019.07.ds249, 2019.
Sharma, V., Comola, F., and Lehning, M.: On the suitability of the Thorpe-Mason model for calculating sublimation of saltating snow, The Cryosphere, 12, 3499-3509, https://doi.org/10.5194/tc-12-3499-2018, 2018.

Sommer, C. G., Lehning, M., and Fierz, C.: Wind tunnel experiments: saltation is necessary for wind-packing, J. Glaciol., 63 , 950-958, https://doi.org/10.1017/jog.2017.53, 2017.

Sommer, C. G., Wever, N., Fierz, C., and Lehning, M.: Investigation of a wind-packing event in Queen Maud Land, Antarctica, The Cryosphere, 12, 2923-2939, https://doi.org/10.5194/tc-12-29232018, 2018.

The IMBIE team: Mass balance of the Antarctic Ice Sheet from 1992 to 2017, Nature, 558, 219-222, https://doi.org/10.1038/s41586-018-0179-y, 2018.

Urbini, S., Frezzotti, M., Gandolfi, S., Vincent, C., Scarchilli, C., Vittuari, L., and Fily, M.: Historical behaviour of Dome C and Talos Dome (East Antarctica) as investigated by snow accumulation and ice velocity measurements, Global Planet. Change, 60, 576-588, https://doi.org/10.1016/j.gloplacha.2007.08.002, 2008.

Vaughan, D. G., Bamber, J. L., Giovinetto, M., Russell, J., and Cooper, A. P. R.: Reassessment of net surface mass balance in Antarctica, J. Climate, 12, 933-946, 1999.

Vionnet, V., Brun, E., Morin, S., Boone, A., Faroux, S., Le Moigne, P., Martin, E., and Willemet, J.-M.: The detailed snowpack scheme Crocus and its implementation in SURFEX v7.2, Geosci. Model Dev., 5, 773-791, https://doi.org/10.5194/gmd-5773-2012, 2012.

Wang, Y., Zhou, D., Bunde, A., and Havlin, S.: Testing reanalysis data sets in Antarctica: Trends, persistence properties, and trend significance, J. Geophys. Res.-Atmos., 121, 12839-12855, https://doi.org/10.1002/2016jd024864, 2016. 